\title{
Estimation of mercury emissions from forest fires, lakes, regional and local sources using measurements in Milwaukee and an inverse method
}

\author{
B. de Foy ${ }^{1}$, C. Wiedinmyer ${ }^{2}$, and J. J. Schauer ${ }^{3}$ \\ ${ }^{1}$ Department of Earth and Atmospheric Sciences, Saint Louis University, MO, USA \\ ${ }^{2}$ National Center of Atmospheric Research, Boulder, CO, USA \\ ${ }^{3}$ Civil and Environmental Engineering, University of Wisconsin - Madison, WI, USA \\ Correspondence to: B. de Foy (bdefoy@slu.edu)
}

Received: 19 April 2012 - Published in Atmos. Chem. Phys. Discuss.: 23 May 2012

Revised: 17 September 2012 - Accepted: 18 September 2012 - Published: 2 October 2012

\begin{abstract}
Gaseous elemental mercury is a global pollutant that can lead to serious health concerns via deposition to the biosphere and bio-accumulation in the food chain. Hourly measurements between June 2004 and May 2005 in an urban site (Milwaukee, WI) show elevated levels of mercury in the atmosphere with numerous short-lived peaks as well as longer-lived episodes. The measurements are analyzed with an inverse model to obtain information about mercury emissions. The model is based on high resolution meteorological simulations (WRF), hourly back-trajectories (WRFFLEXPART) and a chemical transport model (CAMx). The hybrid formulation combining back-trajectories and Eulerian simulations is used to identify potential source regions as well as the impacts of forest fires and lake surface emissions. Uncertainty bounds are estimated using a bootstrap method on the inversions. Comparison with the US Environmental Protection Agency's National Emission Inventory (NEI) and Toxic Release Inventory (TRI) shows that emissions from coal-fired power plants are properly characterized, but emissions from local urban sources, waste incineration and metal processing could be significantly under-estimated. Emissions from the lake surface and from forest fires were found to have significant impacts on mercury levels in Milwaukee, and to be underestimated by a factor of two or more.
\end{abstract}

\section{Introduction}

Elemental mercury emitted to the atmosphere has a lifetime ranging from one half to two years (Lindberg et al., 2007; Schroeder and Munthe, 1998) making it a global pollutant. There is extensive cycling between different stocks of mercury (atmosphere, oceans, lithosphere) which further adds to the time scale and complexity of mercury concentrations in the atmosphere (Selin, 2009). Mercury reacts to form methylmercury which is highly toxic and bioaccumulates in the food chain leading to global health concerns (Mergler et al., 2007).

Before 1970, the main anthropogenic sources were thought to be chloralkali plants, but dominant sources now are coal-fired power plants, waste incineration and metal processing (Schroeder and Munthe, 1998). While some point sources are well characterized with uncertainties within $30 \%$ for power plants for example, sources such as waste incineration and various industrial processes have uncertainties of a factor of five or more (Lindberg et al., 2007). Pirrone et al. (2010) estimate current global natural sources to be $5200 \mathrm{tyr}^{-1}$ and anthropogenic emissions to be $2300 \mathrm{tyr}^{-1}$. Half of the naturally emitted mercury is from the oceans, $13 \%$ from forest fires and most of the balance from vegetation.

Streets et al. (2011) estimate the trend in emissions since 1850, showing a large peak before WWI followed by a decrease during the depression and steady growth over the last $50 \mathrm{yr}$. Atmospheric concentrations are impacted by both fresh emissions of mercury and the re-emissions of deposited 
mercury from terrestrial and aquatic surfaces. Although global emissions of mercury are believed to be increasing, the global average atmospheric concentration of mercury has decreased since the mid-1990s (Slemr et al., 2011). The cause of the discrepancy is unknown. One hypothesis relevant to this study is that there have been significant shifts in the re-emissions of mercury due to climate change, ocean acidification, and excess input of nutrients to terrestrial and aquatic ecosystems (Slemr et al., 2011). As regulatory controls on mercury emissions impact fresh mercury emissions and as re-emissions rates are potentially changing, there is an increased need to develop tools to quantify the emissions of mercury from air pollution sources and to quantify and track re-emissions of legacy mercury in the environment.

Emissions modeling is required to simulate natural sources of mercury, which, as noted above, are thought to account for approximately two thirds of total emissions. Lin et al. (2005) developed an emissions processor using a meteorological model to estimate continental US vegetation emissions between 28 and $127 \mathrm{tyr}^{-1}$ and corresponding impacts of up to $0.2 \mathrm{ng} \mathrm{m}^{-3}$ on average gaseous elemental mercury concentrations. Bash et al. (2004) developed a surface emission model for vegetation, soils and water sources yielding flux estimates in the range of 1.5 to $4.5 \mathrm{ng} \mathrm{m}^{-2} \mathrm{~h}^{-1}$ for the three source types, in agreement with previously published estimates. However, estimates using measurements from a relaxed eddy accumuluation system yielded considerably higher estimates $\left(22 \pm 33 \mathrm{ng} \mathrm{m}^{-2} \mathrm{~h}^{-1}\right)$ above a forest canopy (Bash and Miller, 2008). Further developing the emissions model, Bash (2010) estimate the extensive recycling of mercury that takes place between the atmosphere, terrestrial and surface water stocks. Similar emissions estimates were found by Gbor et al. (2006), who show that including natural emissions improves model performance for total gaseous mercury. Using these estimates, Gbor et al. (2007) find that their domain, which includes the Eastern US and Southeastern Canada, is a net source of mercury to the atmosphere.

Comparison of measurements in coastal and rural sites found impacts of surface water emissions of mercury on atmospheric concentrations (Engle et al., 2010). Ocean emissions were also found to impact mercury levels in New Hampshire (Sigler et al., 2009). A modeling study found that although globally the ocean is a sink of mercury, the North Atlantic is a net source with $40 \%$ of the emissions coming from subsurface water. These are potentially due to historical anthropogenic sources (Soerensen et al., 2010).

Chemical transport modeling of mercury has been developed mainly to estimate deposition rates and is subject to a combination of large uncertainties in emissions as well as in chemical reactions (Lin and Tao, 2003; Roustan and Bocquet, 2006; Seigneur et al., 2004; Bullock et al., 2008). Yarwood et al. (2003) used Eulerian modeling to evaluate mercury deposition in Wisconsin and found that there was a significant need to improve model boundary conditions and the treatment of wet deposition. A further study by Seigneur (2007) found that anthropogenic North American sources likely contributed between 15 and $40 \%$ of mercury deposition in Wisconsin, with less than $10 \%$ contribution from US coal-fired power plants.

Sprovieri et al. (2010) review worldwide measurements of atmospheric mercury and note that there are significant unknowns in the spatial distribution of mercury deposition in relation to sources. For example, there can be low values of deposition close to large power plants in Pennsylvania and Ohio, and high values in Florida. Furthermore, values in urban locations can be a factor of two or greater than at rural sites. Murray and Holmes (2004) had already noted differences by up to a factor of two in different emissions inventories for the Great Lakes and identified that some industrial sources have particularly uncertain emissions. Nevertheless, Cohen et al. (2004) found that estimated deposition rates to the Great Lakes were consistent with measurements. Using a model for particle trajectories, they show that sources up to $2000 \mathrm{~km}$ away can have significant impacts and that coal combustion is the largest contributor although sources such as incineration and metal processing are significant too.

There have been several measurement studies in Wisconsin aimed at identifying sources of mercury. Manolopoulos et al. (2007a) made year long measurements at a rural site and found significant impacts from a local coal-fired power plant on reactive gaseous mercury, but not elemental mercury. They recommend the use of receptor-based monitoring to account for small-scale sources and processes that cannot be represented in large-scale Eulerian models. Kolker et al. (2010) perform a separate study with three rural measurement sites. They find that the site closest to the coal-fired power plant does not always experience the highest mercury levels and suggest three possible reasons: the presence of a chlor-alkali facility, the plume height, and/or the formation of reactive gaseous mercury in the plume. They do find that elevated levels are due to wind transport from the south, but cannot differentiate between local sources or the more distant Chicago area which is in the same direction. Rutter et al. (2008) compare measurements from the rural site reported in Manolopoulos et al. (2007a) and from an urban site in Milwaukee. They report on a significant urban excess in elemental gaseous mercury and suggest that point sources could account for a third of the gaseous elemental mercury in Milwaukee. Further analysis by Engle et al. (2010) includes a comparison of this data with other rural, urban and coastal sites in the US, and further reinforce the suggestion that mercury in Milwaukee is significantly impacted by local point sources.

Measurements studies in other urban locations in the US and Canada reinforce the finding that improvements in mercury inventories are needed, especially because of missing urban point sources. Manolopoulos et al. (2007b) find that in East St. Louis mercury concentrations were more likely influenced by very local sources (within $5 \mathrm{~km}$ ) than by the 
power plants within a $60 \mathrm{~km}$ radius. Liu et al. (2010) find that Detroit has an urban excess in mercury concentrations similar to that reported for Milwaukee. Similar findings were reported for Toronto (Cheng et al., 2009) and for a remote site in Western Ontario (Cheng et al., 2012). Other studies have identified alternative sources such as Taconite mining (Han et al., 2005) as well as melting snow and local mobile sources (Huang et al., 2010). In addition to anthropogenic sources, several studies identified the importance of natural sources, including vegetation sources (Wen et al., 2011) and the Atlantic Ocean (Han et al., 2007).

Inverse methods can be used to estimate regional emissions from measurements of atmospheric concentrations as reviewed in Manning (2011). This has been widely done using Eulerian grid models and is being increasingly applied with Lagrangian Particle Dispersion Models. For example, Lauvaux et al. (2008) use backward trajectories to evaluate emissions based on airborne measurements during a field campaign. Stohl et al. (2009) use a Bayesian formulation to estimate global and regional sources of long-lived atmospheric trace gases (hydrofluorocarbons and hydrochlorofluorocarbons). The sensitivity matrix relating emission sources to atmospheric concentrations is derived using backtrajectories from WRF-FLEXPART. Brioude et al. (2011) use a variant of the method to account for lognormal distribution of the measurements and the prior emission estimates for Houston, Texas. A two-step method is used by Roedenbeck et al. (2009) and Rigby et al. (2011). This combines high resolution back-trajectory simulations for local sources with Eulerian simulations for more distant sources. Manning et al. (2011) use a variable grid resolution for the emissions inversion to take into account the reduced model sensitivity for areas far away from the measurement sites. Furthermore, they use an alternative inversion method based on simulated annealing with a cost function that combines a number of different statistical metrics.

In this study, we combine urban measurements from Milwaukee (Rutter et al., 2008) with meteorological analysis and back-trajectory simulations to identify sources responsible for the gaseous elemental mercury concentrations. We develop a method that is a variant of the inversion method described in Stohl et al. (2009) with elements of the two-step approach of Rigby et al. (2011) and the varying resolution method of Manning et al. (2011). This hybrid inverse model is used to evaluate a range of sources of mercury: local, regional and distant sources, forest fires and lake surface emissions.

We intentionally restrict the study to the transport of gaseous elemental mercury (GEM). This simplifies the inversion method because GEM has an atmospheric lifetime greater than 6 months and so can be treated as a passive tracer. Whereas chemical transformation and deposition are important sources and sinks in the mercury cycle, they do not significantly alter the concentrations of GEM itself on the temporal and spatial scales considered in this study.
In addition to the inverse method, we present a more basic analysis using both wind roses and Concentration Field Analysis (CFA, see Section 2.3) as an independent check on the results. Furthermore, we use a time scale analysis (Section 4.2) to evaluate the limits in temporal resolution of the inverse method and thereby improve the emissions estimate of local sources.

\section{Methods}

\subsection{Measurements}

Ambient mercury measurements were made at an urban site located north of downtown Milwaukee at $2114^{\circ}$ E. Kenwood Blvd, Milwaukee, WI, USA $\left(43^{\circ} 06^{\prime} 29^{\prime \prime} \mathrm{N}, 87^{\circ} 53^{\prime} 02^{\prime \prime} \mathrm{W}\right)$. The location is 0.5 to 1 mile from Lake Michigan. The sampling intake is $1.5 \mathrm{~m}$ above the roof of a two story building. The site is on the southern edge of the campus of the University of Wisconsin - Milwaukee. There are some large structures to the north, but the site is otherwise surrounded by a residential neighborhood. Measurements were made from 28 June 2004 to 11 May 2005 (inclusive). A real time in situ ambient mercury analyzer was used from Tekran, Inc., to measure gaseous elemental mercury (GEM), reactive gaseous mercury (RGM) and particulate mercury ( $\mathrm{PHg}$ ). In this study we focus on the GEM measurements. Ambient air was pumped into the instrument at a rate of $101^{-1} \mathrm{~min}$ for $1 \mathrm{~h}$ followed by $1 \mathrm{~h}$ for analysis of RGM and PHg. GEM was collected onto gold granules over 5 min periods during the hour that RGM and PHg were collected. It was then thermally extracted and measured using Cold Vapor Atomic Fluorescence Spectroscopy (CVAFS). The measurement are described in greater detail in Rutter et al. (2008) and the references therein.

For the meteorological analysis, we use Integrated Surface Hourly Data from the National Climatic Data Center which has hourly wind and temperature observations. The nearest site is at General Mitchell International Airport 10 miles south of the measurement site.

\subsection{Meteorological simulations}

Mesoscale meteorological simulations were performed using the Weather Research and Forecasting Model (WRF) version 3.3.1 (Skamarock et al., 2005). The boundary and initial conditions were obtained from the North American Regional Reanalysis (Mesinger et al., 2006) which has a horizontal resolution of $32 \mathrm{~km}$. WRF was run with two-way nesting on 3 domains of 27, 9 and $3 \mathrm{~km}$ horizontal resolution with 41 vertical levels. Figure 1 shows a map with the three domains. The model set-up is identical to the one described in de Foy et al. (2012).

We used the Yonsei University (YSU) boundary layer scheme (Hong et al., 2006), the Kain-Fritsch convective parameterization (Kain, 2004), the NOAH land surface scheme, 


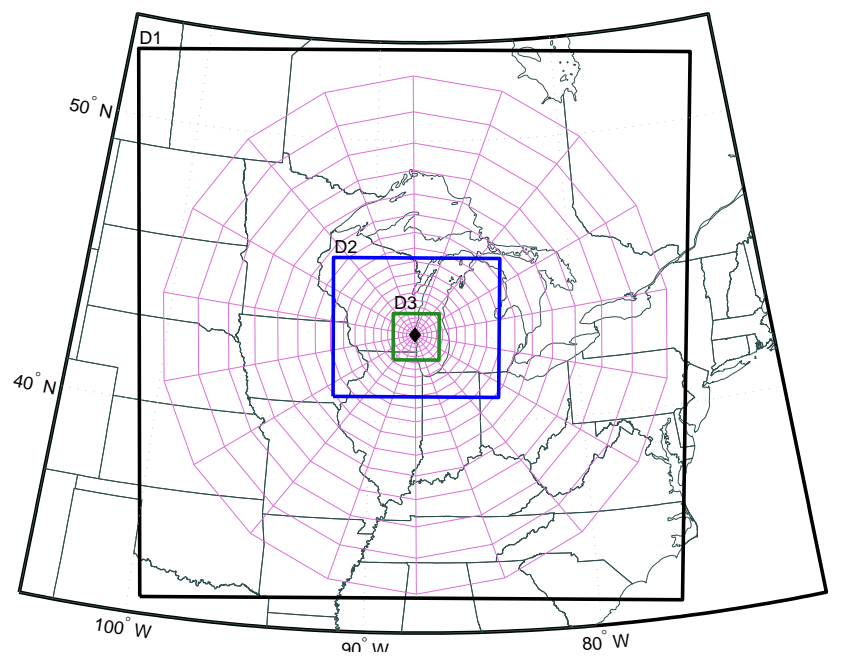

Fig. 1. Map showing the 3 WRF domains (black, blue and green) and the polar grid used for the inverse model (pink) (particle backtrajectories were mapped onto the polar grid for the Residence Time Analysis).

the WSM 3-class simple ice microphysics scheme, the Goddard shortwave scheme and the RRTM longwave scheme. 69 individual simulations were performed each lasting $162 \mathrm{~h}$ : the first $42 \mathrm{~h}$ were considered spin-up time, and the remaining 5 days were used for analysis.

\subsection{Lagrangian simulations}

Stochastic particle trajectories were calculated with FLEXPART (Stohl et al., 2005) using WRF-FLEXPART (Fast and Easter, 2006; Doran et al., 2008). Back-trajectories were calculated for every hour of the campaign by releasing 1000 particles throughout the hour from a randomized height between 0 and $50 \mathrm{~m}$ above the ground. We performed tests with a reduced set of 500 particles per hour to confirm that 1000 particles were sufficient and that the results did not depend on the choice of this parameter. This is consistent with sensitivity tests by Wen et al. (2011) who use 3000 particles per hour. Particle locations were calculated for 6 days and were saved every hour for analysis. Vertical diffusion coefficients were calculated based on the WRF mixing heights and surface friction velocity. Sub-grid scale terrain effects were turned off and a reflection boundary condition was used at the surface to eliminate deposition effects in the Lagrangian model. This is consistent with the treatment of GEM as a passive tracer.

Residence Time Analysis (RTA, Ashbaugh et al., 1985) was obtained by counting all particle positions every hour on a grid. This yields a gridded field representing the time that the air mass has spent in each cell before arriving at the receptor site. The units of this field are in particle $\cdot$ hours. This can be done for different vertical extents. For the Concentration Field Analysis, we count particles in the entire vertical column up to the model top. For the inverse model, we count particles in the bottom $1000 \mathrm{~m}$ as discussed in Section 2.6.

The RTA can be used for a Concentration Field Analysis (CFA, Seibert et al., 1994) to identify potential source regions using concentration measurements at a receptor site, see also (de Foy et al., 2009, 2007). Results will be presented using the GEM concentrations and a grid with $45 \mathrm{~km}$ resolution that covers most of WRF domain 1.

For the inverse method, the choice of grid has a much greater impact on the results. It is important to choose a grid that has a resolution similar to the resolution capability of the models. Manning et al. (2011) use a rectangular grid with variable grid sizes to enable high resolution of emissions close to the source and much larger grid sizes farther away. In this work, we choose a polar grid with increasing radial distance further from the source, as shown in Fig. 1. After testing different options, we selected a grid with 18 cells in the circumferential direction and 20 in the radial direction. It has a $20^{\circ}$ resolution and an initial radial distance of $10 \mathrm{~km}$ increasing linearly by $15 \%$ reaching a maximum radial grid thickness of $142 \mathrm{~km}$ at a distance of $1024 \mathrm{~km}$. Overall, this choice of grid leads to an inversion of 371 variables using 3954 measurement points which preserves a ratio of 10 data points per free variable.

\subsection{Lake surface emissions}

Emissions of mercury from the lake surfaces were calculated using the method described in $\mathrm{Ci}$ et al. (2011a,b). This is based on a two-layer gas exchange model described by Eq. (1):

$F=K_{\mathrm{w}}\left(C_{\mathrm{w}}-C_{\mathrm{a}} / H^{\prime}\right)$

$F$ is the GEM flux in $n g \mathrm{~m}^{-2} \mathrm{~h}^{-1} . K_{\mathrm{w}}$ is the water mass transfer coefficient given by Wanninkhof (1992), which is a function of the surface wind speed and the Schmidt number. The Schmidt number is defined as the kinematic viscosity divided by the aqueous diffusion coefficient of elemental mercury. Kuss et al. (2009) determined the diffusion coefficient and found that it is nearly identical to that for carbon dioxide for the temperature range of interest. The parameterizations for the latter can therefore be used for the former in the present case. $H^{\prime}$ is the Henry's Law constant and is based on the lake temperature. $C_{\mathrm{w}}$ is the concentration of Dissolved Gaseous Mercury (DGM) in the surface waters, measured in $\mathrm{pg}^{-1}$, and $C_{\mathrm{a}}$ is the concentration of atmospheric GEM measured in $\mathrm{ng} \mathrm{m}^{-3}$. Overall, the emissions fluxes from $\mathrm{Ci}$ et al. (2011a) are higher but follow a similar pattern as those estimated from the parameterization of Poissant et al. (2000).

The Great Lakes are super-saturated in mercury with respect to the atmosphere such that the flux is from the water to the air (Vette et al., 2002; Poissant et al., 2000). For $C_{\mathrm{a}}$ we use a background value of $1.5 \mathrm{ng} \mathrm{m}^{-3}$, as reported by Rutter et al. (2008). For $C_{\mathrm{w}}$, Poissant et al. (2000) report measurements made in 1998 of 50 to $130 \mathrm{pgl}^{-1}$ during a transect of 
Table 1. Total emissions from lake surface emissions for the 318 days of the measurements for the domains shown in Fig. 2.

\begin{tabular}{lrr}
\hline Lake & $\begin{array}{r}\text { Emissions } \\
(\mathrm{kg})\end{array}$ & $\begin{array}{r}\text { Average flux } \\
\left(\mathrm{ng} \mathrm{m}^{-2} \mathrm{~h}^{-1}\right)\end{array}$ \\
\hline Michigan & 1698 & 2.7 \\
Superior & 2396 & 2.6 \\
Huron & 1687 & 2.1 \\
Erie & 657 & 2.3 \\
Ontario & 412 & 2.0 \\
\hline Total & 6849 & 2.3 \\
\hline
\end{tabular}

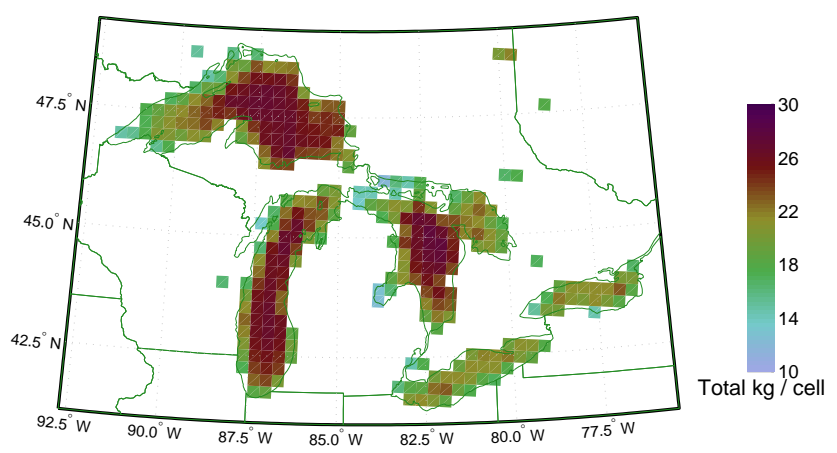

Fig. 2. Gaseous elemental mercury emissions from the lake surfaces summed from 28 June 2004 to 11 May 2005 for WRF domain 1. See Table 1 for total emissions from each lake. Areas with zero emissions shown in white.

Lake Ontario and around $30 \mathrm{pg}^{-1}$ in the Upper St. Lawrence River. These are on the high end of measurements reported in the literature (Lai et al., 2007) which found values of $16 \mathrm{pg}^{-1}$ in Lake Ontario. For Lake Michigan, Vette et al. (2002) found DGM concentrations around $20 \mathrm{pgl}^{-1}$ during measurements in 1994 . We chose to use $30 \mathrm{pgl}^{-1}$ as a domain wide average in this study.

The emissions were calculated for WRF domains 1 and 2 using lake temperatures interpolated from the NARR, and hourly $10-\mathrm{m}$ wind speeds from the model. WRF domain 1 covers all five of the Great Lakes and domain 2 covers Lake Michigan. Figure 2 shows the map of emissions of GEM summed over the duration of the campaign. Total emissions and average fluxes are reported for each lake in Table 1. Total emissions from the 5 lakes were $6849 \mathrm{~kg} \mathrm{yr}^{-1}$ for 318 days, and average fluxes were $2.3 \mathrm{ng} \mathrm{m}^{-2} \mathrm{~h}^{-1}$.

Concentrations of GEM due to lake surface emissions were simulated at the receptor site using the Comprehensive Air-quality Model with eXtensions (CAMx, ENVIRON, 2011), version 5.40. This was run on WRF domains 1 and 2 (resolution 27 and $9 \mathrm{~km}$ ) with the first 18 of the 41 vertical levels used in WRF using the O'Brien vertical diffusion coefficients (O'Brien, 1970).

During the testing of the inverse model, the estimates of the lake emissions were very robust across different time se-
Table 2. Total emissions of GEM from forest fires for the 318 days of the measurements for the domains shown in Fig. 3.

\begin{tabular}{lr}
\hline Domain & Emissions $(\mathrm{kg})$ \\
\hline WRF D2 & 1383 \\
East & 7521 \\
Southeast & 43305 \\
South central & 15987 \\
North central & 7157 \\
West & 8914 \\
Pacific Northwest & 46329 \\
Northern Canada & 76903 \\
Alaska & 85116 \\
\hline Total & 292595 \\
\hline
\end{tabular}

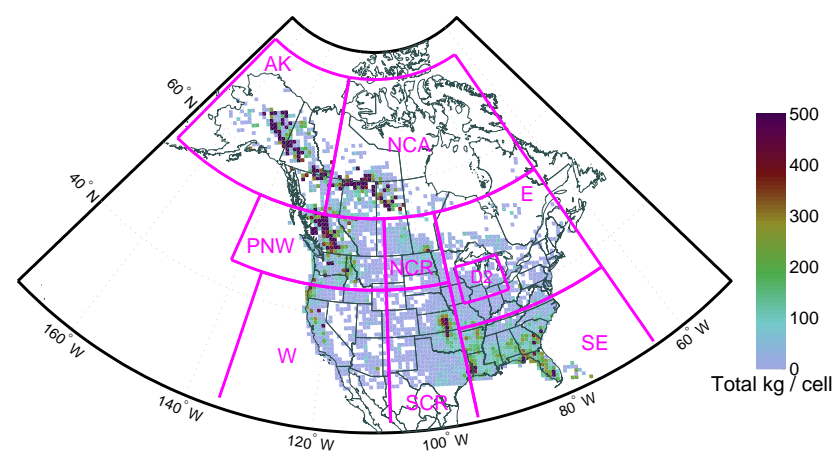

Fig. 3. Forest fires emissions from 28 June 2004 to 11 May 2005, showing the different domains used: Alaska (AK), Northern Canada (NCA), pacific northwest (PNW), west (W), north central (NCR), south central (SCR), east (E), southeast (SE). Note that the east domain does not include WRF domain 2 (D2) which is calculated separately. The maximum emissions in a cell is $7224 \mathrm{~kg}$, in Alaska. See Table 2 for total emissions by domain. Areas with zero emissions shown in white.

lections except for two time periods: from 28 June to 18 July, and from 1 to 11 August 2004. Pending further analysis, these two time periods were therefore removed from the time series, as can be seen if Fig. 10.

\subsection{Forest fires}

Emissions of mercury from open fires, including wildfires, agricultural burning and prescribed burns, were calculated using the Fire INventory from NCAR (FINN) version 1, an emission framework method described in Wiedinmyer et al. (2006) and Wiedinmyer et al. (2011). Fire counts for North America were downloaded from the US. Forest Service Remote Sensing Applications Center for 2003 through 2005 (http://activefiremaps.fs.fed.us/gisdata. php?sensor=modis\&extent=north_america). These data are from the Terra and Aqua MODIS fire and thermal anomalies data provided from the official NASA MCD14ML product, Collection 5, version 1 (Giglio et al., 2003). Land cover and 
vegetation density was determined with the MODIS Land Cover Type product (Friedl et al., 2010) and the MODIS Vegetation Continuous Fields product (Collection 3 for 2001) (Hansen et al., 2003, 2005; Carroll et al., 2011), and fuel loadings from Hoelzemann et al. (2004) and Akagi et al. (2011). Emission factors for mercury emissions were provided by Wiedinmyer and Friedli (2007).

Figure 3 shows the sum of the emissions over the duration of the measurements. This domain covers the continental US and most of Canada, which is much larger than WRF domain 1 used above. We therefore perform a second set of meteorological simulations with a single domain of 121 by 91 cells and a resolution of $64 \mathrm{~km}$. We separate the emissions into sub-domains shown in Fig. 3 and perform individual CAMx simulations for each one. In this way, we obtain time series of concentrations at the measurement site due to fires in the following geographical areas: Alaska, Northern Canada, pacific northwest, west (mainly fires in California and Southern Oregon), north central, south central, southeast and east. Fires within WRF Domain 2 are simulated separately from the rest of the east domain using the higher resolution WRF simulations above.

\subsection{Inverse method}

Because gaseous elemental mercury is a long-lived species, we can assume a linear relationship between an emissions vector $\boldsymbol{x}$ and the measurements $\boldsymbol{y}$ given by the sensitivity matrix H (Rigby et al., 2011; Brioude et al., 2011; Stohl et al., 2009; Lauvaux et al., 2008):

$\boldsymbol{y}=\mathbf{H} \boldsymbol{x}+$ residual

The sensitivity matrix is composed of any terms that relate emissions to concentrations. For example, it can include time series of concentrations using a priori emissions, or Residence Time Analysis from back-trajectory simulations, or constant terms to represent background concentrations.

Following Tarantola (1987) and Enting (2002), and as described in the papers above, we can write the cost function $J$ as the sum of the cost function for the observations and for the emissions vector:

$J=J_{\mathrm{obs}}+J_{\mathrm{emiss}}$

We use a damped least-squares formulation to obtain estimates of the emissions vector $\boldsymbol{x}$ as described in Aster et al. (2012) (Eq. 4.4) and Wunsch (2006) (Eq. 2.114), which is based on the method of Tikhonov regularization:

$J=\|(\mathbf{H} \boldsymbol{x}-\boldsymbol{y})\|_{2}+\alpha^{2}\|\boldsymbol{x}\|_{2}$

This introduces a regularization parameter $\alpha$ to balance the two terms of the cost function and was used to estimate sulfur emissions using trajectory models by Eckhardt et al. (2008); Seibert (2000).
The sensitivity matrix $\mathbf{H}$ can be composed of multiple components, as was done in Rigby et al. (2011). In this work, we combine the sensitivities from the back-trajectories obtained using WRF-FLEXPART, the sensitivities from forward simulations using CAMx and the sensitivities due to background values:

$\mathbf{H}=\left(\mathbf{H}_{\mathrm{RTA}}, \mathbf{H}_{\mathrm{CAMx}}, \mathbf{H}_{\mathrm{Bkg}}\right)$

$\boldsymbol{x}=\left(\boldsymbol{x}_{\mathrm{RTA}}, \boldsymbol{x}_{\mathrm{CAMx}}, \boldsymbol{x}_{\mathrm{Bkg}}\right)^{T}$

$\mathbf{H}_{\text {RTA }}$ is the Residence Time Analysis from WRFFLEXPART. Each column contains the time series of concentrations that would be expected at the measurement site given a unit of emission from a particular grid cell. $\boldsymbol{x}_{\mathrm{RTA}}$ contains emissions from each cell of the polar grid (see Fig. 1), in units of mass per time. Multiplying the emissions in $\boldsymbol{x}_{\mathrm{RTA}}$ by the concentrations per emissions in $\mathbf{H}_{\text {RTA }}$ leads to concentration contributions for vector $\boldsymbol{y}$ from the polar grid.

$\mathbf{H}_{\text {CAMx }}$ contains time series of concentrations obtained from CAMx simulations using the emissions from the lakes and from the forest fires described in Sects. 2.4 and 2.5. $\boldsymbol{x}_{\mathrm{CAMx}}$ contains scaling factors on these emissions to obtain actual contributions to concentrations in vector $\boldsymbol{y}$.

Finally, $\mathbf{H}_{\mathrm{Bkg}}$ consists of a column of ones to represent a constant background, with the actual background value contained in $\boldsymbol{x}_{\mathrm{Bkg}}$. Note that additional columns could be placed here to have a varying background in time, although this was not retained for this analysis.

If we have a priori values $\boldsymbol{x}_{o}$ for the emissions factors $\boldsymbol{x}$, we modify the equations to solve for adjustments to the a priori emissions factors $\left(\boldsymbol{x}^{\prime}\right)$ instead of solving for emissions factors directly:

$x^{\prime}=x-x_{o}$

$\boldsymbol{y}^{\prime}=\boldsymbol{y}-\mathbf{H} \boldsymbol{x}_{o}$

In order to simplify the solution of the system, the cost function of the emissions vector $J_{\text {emiss }}$ can be folded into $J_{\text {obs }}$ by augmenting the sensitivity matrix $\mathbf{H}$ with diagonal terms and the observation vector $\boldsymbol{y}$ with zero values, see also Eq. 4.5 in Aster et al. (2012):

$J=\left\|s \cdot\left(\mathbf{H}^{\prime \prime} \boldsymbol{x}-\boldsymbol{y}^{\prime \prime}\right)\right\|_{2}$

Where $\mathbf{H}^{\prime \prime}=(\mathbf{H}, \mathbf{I})$ and $\boldsymbol{y}^{\prime \prime}=\left(\boldsymbol{y}, \boldsymbol{x}_{\text {zero }}\right)^{T}$ are the augmented versions of $\mathbf{H}$ and $\boldsymbol{y}$ (or of $\mathbf{H}^{\prime}$ and $\boldsymbol{y}^{\prime}$ if using a priori emissions). $\mathbf{I}$ is the identity matrix the size of $\boldsymbol{x}$, and $\boldsymbol{x}_{\text {zero }}$ is a vector of zero values. The vector $s$ consists of the scaling factors of the cost function: unit values for the observation cost function and $\alpha$ for the emissions cost function.

The regularization parameter $\alpha$ balances the importance of the cost function of the measurements with that of the emissions factors. In the current setup it has units of concentration $\left(\mathrm{ng} \mathrm{m}^{-3}\right)$ divided by emissions $\left(\mathrm{lbyr}^{-1}\right)$. If a small value is 
chosen, there will be weak constraints on the vector $x$ leading to a better fit with the obervations at the risk of unrealistically large emissions. Larger values of $\alpha$ reduce the magnitude of the emissions at the cost of a poorer fit with the observations. Hansen (2010) discusses different methods for selecting the parameter. Based on testing, we use a value of $1 \times 10^{-4}$ for the grid cell emissions in $\boldsymbol{x}_{\text {RTA }}$ and zero for the CAMx scaling factors and the background.

The purpose of using this formulation is to simplify the equation to a single least-squares problem so that constraints can be applied easily to the emissions vector $\boldsymbol{x}$. Solution methods for Eq. (4) will generate negative emission values by default (Stohl et al., 2009; Brioude et al., 2011). These corrupt the solution by obtaining an excellent fit for the linear model (Eq. 2) from a combination of unphysical values. Stohl et al. (2009) solve this problem by iteration. After each solution, the error covariance terms are adjusted to force the posterior emissions closer to the a priori emissions for those points that would be negative. Brioude et al. (2011) address the problem by working with the log of the concentrations. In this work, we apply constraints on the solution of the linear least-squares problem directly in Eq. (9). We apply a lower bound so that all emissions are positive but do not specify an upper bound on $\boldsymbol{x}$. In this way, the solution $\boldsymbol{x}$ can be found by straightforward application of the Matlab function lsqlin.

One drawback of using the least-squares formulation is that it is sensitive to outliers. We seek to make the solution more robust by excluding data points where there is a large discrepancy between the model and the data. After the first solution of the least-squares problem, the magnitude of the residual in Eq. (2) is used to refine estimates of $\boldsymbol{s}_{i}$. Observation times that have a residual larger than 3 times the standard deviation of the residual values are assigned a scaling factor of 0 . This process converges on a stable set of values of $s$ after 2 to 4 iterations.

The Residence Time Analysis (RTA) has units of particle - hours which needs to be converted for the sensitivity matrix $\mathbf{H}_{\text {RTA }}$. The measurements $\boldsymbol{y}$ are in units of $\mathrm{ng} \mathrm{m}^{-3}$ and the emissions $\boldsymbol{x}$ were calculated in units of $\mathrm{lbyr}^{-1}$ to be consistent with the EPA emissions inventories. We therefore need to scale the RTA matrix by a factor with units of $\mathrm{nglb}^{-1} \cdot \mathrm{yrh}^{-1} \cdot(\text { particle } \cdot \text { volume })^{-1}$. For the last term on the right we use the maximum number of particles in a simulation (1000 in our case) multiplied by the volume of the grid cells in the Residence Time Analysis. The height of the cells used for counting particles to obtain the RTA matrix must be chosen to be large enough to have a sufficient number of particle counts, and small enough to provide a value that is related to the measurements which are surface concentrations. In practice, we choose a value of $1000 \mathrm{~m}$ which corresponds to the mixing height for the time scales corresponding to the transport distances in the polar grid used. Note that the sensitivity matrix can end up with very small values which can hinder the computational solution of the system of equations. This can be improved by introducing a scaling factor on $\mathbf{H}$ and $\boldsymbol{x}$ which reduces the computation time without changing the results.

\subsubsection{Comparison with Bayesian derivation}

Another way of understanding the regularization parameter $\alpha$ can be found by comparing the least-squares formulation with the Bayesian formulation of the problem. The cost function in Eq. 3 can be written as (Lorenc, 1986; Tarantola, 1987; Enting, 2002):

$J=(\mathbf{H} \boldsymbol{x}-\boldsymbol{y})^{T} \mathbf{R}_{a}^{-1}(\mathbf{H} \boldsymbol{x}-\boldsymbol{y})+\boldsymbol{x}^{T} \mathbf{R}_{b}^{-1} \boldsymbol{x}$

Where $\mathbf{R}_{a}$ is the measurement/model uncertainty covariance and $\mathbf{R}_{b}$ is the error covariance matrix on the emissions factors in $\boldsymbol{x}$.

The two parts of the cost function can be merged as for Eq. (9) to yield:

$J=\left(\mathbf{H}^{\prime \prime} \boldsymbol{x}-\boldsymbol{y}^{\prime \prime}\right)^{T} \mathbf{R}^{-1}\left(\mathbf{H}^{\prime \prime} \boldsymbol{x}-\boldsymbol{y}^{\prime \prime}\right)$

Where $\mathbf{H}^{\prime \prime}, \boldsymbol{y}^{\prime \prime}$ and $\boldsymbol{x}$ are the same as in Eq. (9), and the matrix $\mathbf{R}^{-\mathbf{1}}$ is the combination of $\mathbf{R}_{a}^{-1}$ and $\mathbf{R}_{b}^{-1}$ along the diagonal, with zero values for the upper-left hand and lower-right hand blocks.

The error covariance matrices are often taken to be diagonal matrices because of a lack of information on the offdiagonal elements (Brioude et al., 2011; Stohl et al., 2009). The Bayesian cost function in Eq. (11) therefore simplifies to the least-squares formulation in Eq. (9) as described in Sect. 2.4 of Wunsch (2006), and the vector $s$ contains the diagonal elements of $\mathbf{R}^{\mathbf{- 1}}$.

If we have constant values for the variance of the observations, $\sigma_{a}$, and the variance of the emissions vector, $\sigma_{b}$, we obtain $\mathbf{R}_{a}=\sigma_{a}^{2} I$ and $\mathbf{R}_{b}=\sigma_{b}^{2} I$. $\mathbf{R}$ can be rescaled to derive the following relationship:

$\alpha=\frac{\sigma_{a}}{\sigma_{b}}$

The regularization parameter $\alpha$ can therefore be derived from the Bayesian perspective, as was done in (Brioude et al., 2011; Henze et al., 2009). The standard deviation $\sigma_{a}$ of the measurements is approximately $1 \mathrm{ng} \mathrm{m}^{-3}$ and an estimate of the standard deviation $\sigma_{b}$ of the emissions is approximately $10000 \mathrm{lbyr}^{-1}$ leading to a value of $\alpha=1 \times 10^{-4}$, in agreement with the value that was determined empirically.

\subsubsection{Model uncertainty}

Sources of uncertainty in the inversion arise from modelmeasurement mismatch errors, aggregation errors and systematic model errors. Model-measurement mismatch errors occur when the measurements reflect sources that cannot be simulated with sufficient accuracy by the model. This leads to large residuals, especially for short concentration spikes that are most likely from local plumes. Aggregation errors 


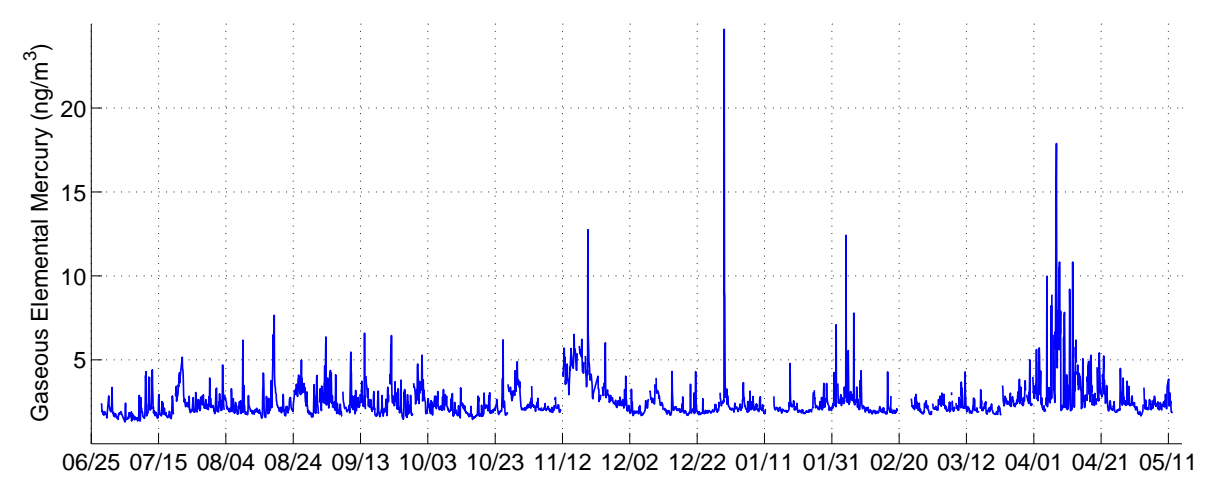

Fig. 4. Time Series of elemental gaseous mercury in Milwaukee from 28 June 2004 to 11 May 2005. This shows a combination of variations across time scales from short peaks lasting hours or less to longer events lasting days or even weeks.

result from spatial and temporal averaging (Thompson et al., 2011). The polar grid was designed so that the model results would be averaged spatially on a scale similar to the resolving power of the model: smaller cells close to the measurement site increasing in size with distance from the site. Temporally, both measurements and model output are on an hourly scale. However the meteorological simulations perform better at the sesonal and synoptic time scales than at the intra-day time scale. Furthermore, the simulated emissions are constant in time for the back-trajectories, and the scaling factors for the Eulerian grid simulations are fixed. To address these we therefore perform a time scale analysis in Sect. 4.2 to quantify how much of the measured and inverted signal there is at different time scales.

Systematic errors can also introduce significant biases in the model, for example if the inversion consistently identifies sources too far away. To deal with this, we perform a synthetic test in Sect. 3.1 to demonstrate the inverse method's ability to identify an individual source. With respect to possible systematic transport errors, these need to be evaluated by comparing the inverse results with known sources. These include for example the coal fire power plants in the Ohio River Valley, which are shown in Sect. 4.1 to be correctly identified.

\subsubsection{Confidence intervals with bootstrapping}

To obtain a posteriori confidence intervals on the results, we use the bootstrap method. Multiple instances of the model are run with a random selection, with replacement, of both the measurement data points and the emission factors. Measurement data points used in the analysis are randomly selected leading to a modified measurement vector $\boldsymbol{y}$ and corresponding selection of the rows in $\mathbf{H}$. Emission factors from the particle grid $\left(\boldsymbol{x}_{\mathrm{RTA}}\right)$ are also randomly selected leading to rearrangement of the columns of $\mathbf{H}_{\text {RTA }}$. We also performed tests where the CAMx time series were used with a probability of $75 \%$ in any given simulation. This was chosen arbitrarily to test for the sensitivity of the results to the selection of
CAMx simulations. In practice, the results were robust with respect to the selection and so this option was not used for the simulations presented here.

\section{Results}

Before describing the inverse method, we present a preliminary analysis using simpler methods. Figure 4 shows the time series of elemental gaseous mercury concentrations, which was analyzed by Rutter et al. (2008). As described above, there are 3594 data points which are hourly concentrations measured on alternate hours from 28 June 2004 to 11 May 2005 (inclusive). There are a combination of features ranging from the hourly scale to the daily and weekly scale. High peaks of short duration suggest narrow plumes from point sources. These were estimated to make up one third of the GEM in Rutter et al. (2008). Longer peaks such as in the second half of November 2004 or during April 2005 suggest larger scale phenomena.

Figure 5 shows windroses corresponding to low, high and very high GEM levels. The dominant winds during concentrations in the bottom $50 \%$ are from the northwest. For high concentrations, defined as being in the $50 \%$ to $95 \%$ range, the winds are predominantly from the south-southwest and from the north-northeast. The top $5 \%$ of concentrations take place when there are winds from the northeast and from the southwest. The bars in the windroses are colored by time of day and show that the northeast winds are associated with afternoon winds whereas the southwest winds are more likely to be before sunrise.

Figure 6 shows the Residence Time Analysis and the Concentration Field Analysis for a domain covering most of WRF domain 1 for the entire time period. The RTA is in agreement with the windroses and shows that the dominant wind transport to Milwaukee is from the northwest, from the northeast over Lake Michigan and from the south-southwest through Illinois. The southeast area has the smallest contribution to airmass transport at the receptor site. The CFA shows 

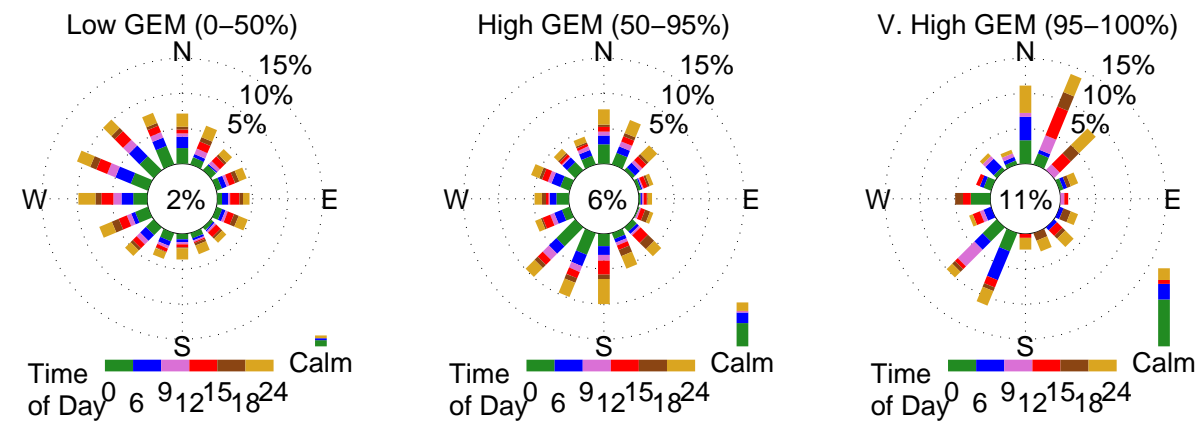

Fig. 5. Wind roses separated according to concentrations of gaseous elementa 1 mercury. Left: $1780 \mathrm{~h}$ with concentrations in the bottom $50 \%$, middle: $1636 \mathrm{~h}$ with concentration in the 50 to $95 \%$ interval and right: $179 \mathrm{~h}$ with concentrations in the top $5 \%$. The dominant wind direction for low values is from the northwest, for high values it is from the south/southwest and from the north, and for the highest peaks it is from the northeast and from the southwest. Percentage of hours with calm winds shown in the middle circle.
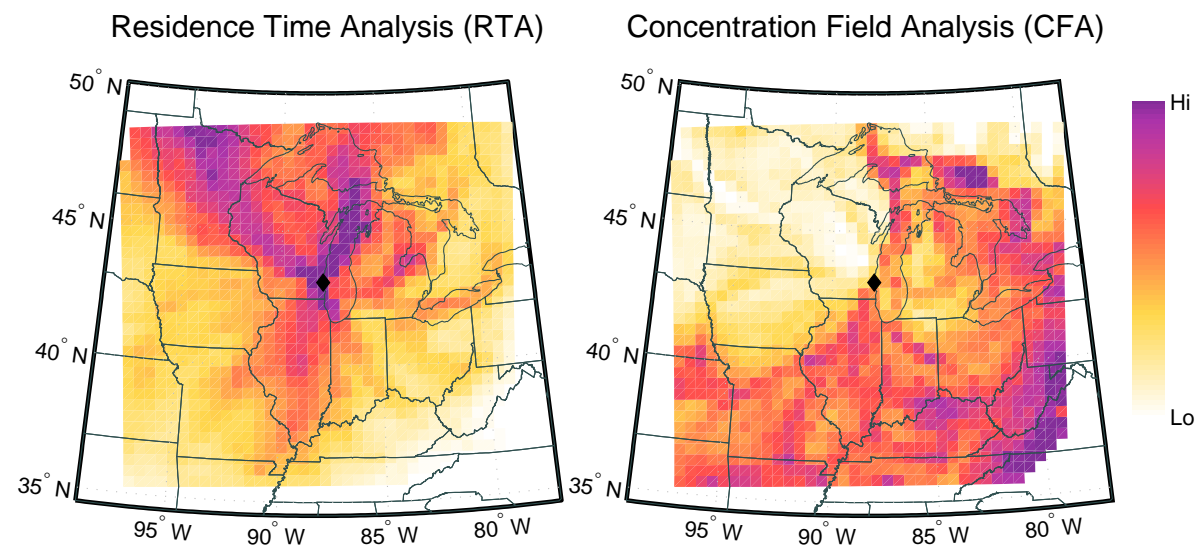

Fig. 6. Residence Time Analysis (RTA, left) and Concentration Field Analysis (CFA, right) for hourly back-trajectories from Milwaukee from 28 June 2004 to 11 May 2005. Measurement site shown by the diamonds. RTA shows dominant surface transport from the northwest, over the lake from the northeast, and from the south through Illinois. CFA shows low potential source regions to the northwest, medium to the south and north and highest towards the Ohio River Valley.

that there are unlikely to be significant mercury sources to the northwest, in agreement with the windroses. The northeast signature in the windroses corresponds to a significant potential source region over the Great Lakes in the CFA analysis. Finally, south-southwest transport of mercury to Milwaukee corresponds to transport from industrial regions to the south. As CFA does not distinguish easily between positions along the plume path, these could be a combination of local sources south of the measurement site, more distant sources from the Chicago area or sources beyound that. Althouh the airmass does not frequently come over the Ohio River Valley, when it does it is associated with high GEM levels.

\subsection{Synthetic inverse}

The inverse method was tested using synthetic data corresponding to continuous emissions from a single point $213 \mathrm{~km}$ to the northwest of the measurement site. There were no other sources in the simulation. Synthetic concentrations were simulated using CAMx as input for the inversion. Zero a priori values were used in order to provide a stringent test. Residual scaling was applied and converged on the fourth iteration, with 177 measurements excluded from the analysis (out of a total of 7657). Figure 7 shows the map of the inverse emissions, clearly showing that the model correctly identifies the source cell. The emission strength from the actual emission grid cell was underestimated by $25 \%$. If we include the neighboring grid cells in the emission strength, then the underestimate is reduced to $18 \%$. Over the whole domain, there is an over-estimation of the emissions by $21 \%$. The net result of this is that $68 \%$ of the emissions in the inversion come from the correct area (calculated by taking $82 \%$ of the source strength out of $121 \%$ total simulated emissions).

One can see from the emissions map (Fig. 7) that the model is better at resolving the direction of the source than the distance from the source. Furthermore, the model has a tendency to overestimate distant sources. This happens if the particular grid cells happens to have a single impact that coincides with a high concentration peak at the measurement 
site. There are three ways of mitigating this problem in the current setup. The first is by using a polar grid with increasing cell sizes. This makes it less likely to have a chance correlation between the RTA and the concentrations. The second is to use iterative residual scaling which prevents the scheme from trying to match peaks that it cannot resolve. The third is to use the regularization parameter $\alpha$ which balances the cost function between the measurements and the emissions factors. By increasing this, the model will reduce the overal amount of predicted emissions.

\subsection{Full inverse}

The inversion algorithm was run on the actual data (3594 data points) using the polar grid consisting of 360 grid cells, the 9 CAMx concentration time series for the forest fires domains, one CAMx concentration time series for the lake surface emissions and a single value for the background. The augmented matrix $\mathbf{H}^{\prime \prime}$ contains a further 360 rows with the weighting factors in the diagonal. This leads to the solution of a linear system of equations with dimensions of $3954 \times 371$. Because the actual inversion takes of the order of one second to run on a desktop, it can be easily carried out for 100 bootstrapped simulations of 5 iterations each. The 5 iterations allow the residual scaling to converge. Testing with up to 1000 bootstrapped runs showed that 100 simulations were sufficient to provide a measure of uncertainty on the solution vector $\boldsymbol{x}$. For the simulations presented we do not use a priori emissions, instead leaving the inversion algorithm to identify source regions irrespective of previous estimates. Sensitivity testing on the determination of the regularization parameter $\alpha$ and the use of a priori values suggests that the spatial distribution of the sources and the CAMx scaling factors are robust, but that the magnitude of the grid emissions are more sensitive to the model setup.

Figure 8 shows the inverse emissions grids in units of $\mathrm{kg} \mathrm{yr}^{-1}$, using the median of the 100 bootstrapped runs. Table 3 shows the total emissions, tabulated according to the geographic region for the domains shown in Fig. 11. The table also shows the lower quartile and upper quartile values of the bootstrapped simulations which represent a measure of the variability of the results.

The largest sources are from grid cells over the Ohio River Valley to the southeast, which is an area known for its large coal-fired power plants. Overall, the model estimates emissions of $23000 \mathrm{~kg} \mathrm{yr}^{-1}$ from the southeast domain. The southwest domain emissions are estimated to be $24000 \mathrm{~kg} \mathrm{yr}^{-1}$ from a larger number of grid cells corresponding to emissions from a broader area. After this, the northeast domain accounts for $13000 \mathrm{~kg} \mathrm{yr}^{-1}$ coming from upper Michigan, Eastern Canada, the US Northeast, Lake Huron and Lake Superior. The remaining domains have lower estimated emissions. To the northwest there are $6000 \mathrm{~kg} \mathrm{yr}^{-1}$ from the upper Great Plains. Closer in, there are $3500 \mathrm{~kg} \mathrm{yr}^{-1}$ from regional sources to the west and $6000 \mathrm{~kg} \mathrm{yr}^{-1}$ from re-

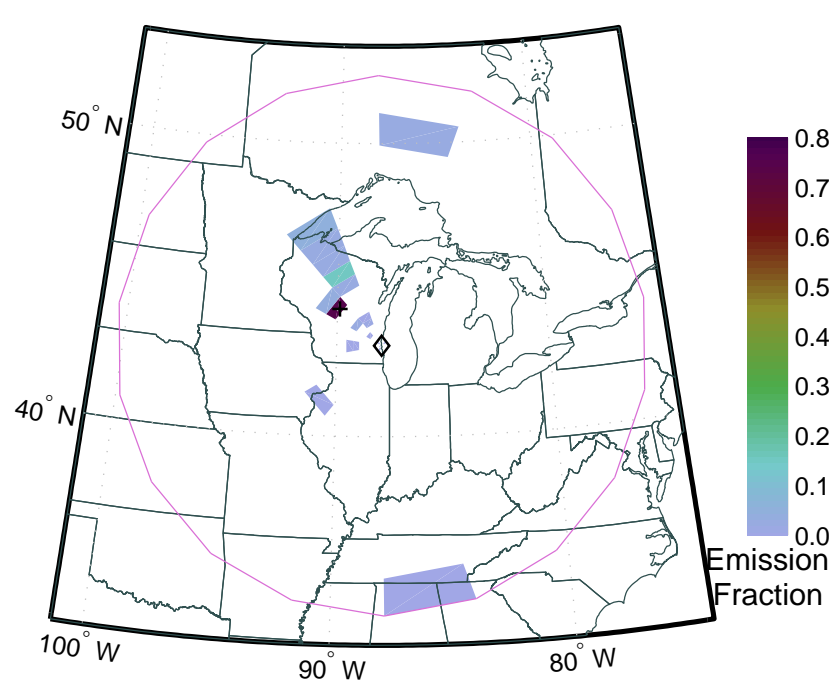

Fig. 7. Map of emissions from the inverse model using synthetic simulations from a location (+) $213 \mathrm{~km}$ northwest of the receptor site (diamond). Units are fraction of the synthetic release. Extent of the back-trajectory grid used for the inversion shown in pink. Areas with zero emissions shown in white.

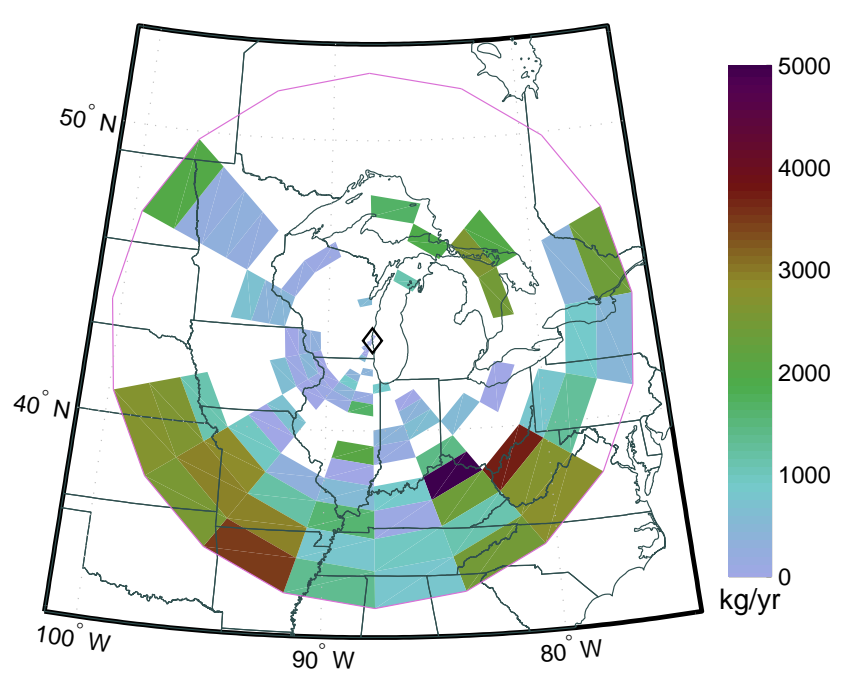

Fig. 8. Map of inverse gridded emissions showing the median of 100 bootstrapped runs. Extent of the back-trajectory grid used for the inversion shown in pink. Areas with zero emissions shown in white.

gional sources to the south, which include Chicago. The local domain counts sources within a $50 \mathrm{~km}$ radius of the measurement site, for a total of $1000 \mathrm{~kg} \mathrm{yr}^{-1}$.

Figure 9 shows histograms of the scaling factors applied to the CAMx simulated time series of forest fires and lake surface emissions. Median, lower quartile and upper quartile values are shown in Table 4 . The lake surface emissions have a very reliable scaling factor with a median value of 1.9 and an interquartile range of 1.7 to 2.2 . This suggests that the results are robust relative to the selection of time periods and 
Table 3. Comparison of emission estimates from the inverse model (shown in Fig. 8) with those from the US Environmental Protection Agency's Toxic Release Inventory (TRI) and National Emission Inventory (NEI) (shown in Fig. 13). Median, lower-quartile and upperquartile values are obtained from 100 bootstrapped runs of the inverse model. Emission amounts are tabulated according to the geographical domains shown in Fig. 11.

\begin{tabular}{lrrrrrr}
\hline Emissions (kgyr & Median & Lower-quartile & Upper-quartile & TRI 2004 & GEM NEI 2002 & Hg NEI 2002 \\
\hline Local (50 km radius) & 984 & 835 & 1164 & 217 & 71 & 193 \\
South regional & 6071 & 5023 & 7503 & 1887 & 1551 & 3248 \\
Northeast & 13198 & 10569 & 17194 & 1510 & 578 & 2276 \\
Southeast & 23003 & 19761 & 26391 & 17658 & 6035 & 25603 \\
West regional & 3523 & 2662 & 4922 & 1158 & 251 & 1430 \\
Southwest & 23770 & 20942 & 27367 & 7163 & 3796 & 9701 \\
Northwest & 5761 & 4331 & 7346 & 1582 & 832 & 3480 \\
\hline Total & 76310 & 64123 & 91887 & 31176 & 13114 & 45932 \\
\hline
\end{tabular}

Table 4. Scaling factors for forest fires emissions and lake surface emissions shown in Fig. 9.

\begin{tabular}{lccc}
\hline Domain & Median & Lower-quartile & Upper-quartile \\
\hline WRF D2 & 0 & 0 & 0 \\
East & 3.9 & 3.1 & 4.5 \\
Southeast & 1.1 & 0.6 & 1.6 \\
South central & 1.2 & 0.8 & 1.6 \\
North central & 2.6 & 2.2 & 3.3 \\
West & 6.7 & 3.9 & 10.1 \\
Pacific northwest & 0.0 & 0.0 & 0.0 \\
Northern Canada & 0.1 & 0.0 & 0.2 \\
Alaska & 0 & 0 & 0 \\
\hline Lake surface & 1.9 & 1.7 & 2.2 \\
\hline
\end{tabular}

are not sensitive to the selection of grid points or forest fires time series included in the inversion.

The forest fires factors vary across the domains shown in Fig. 3. The most reliable result is a median factor of 3.9 (inter-quartile range 3.1 to 4.5 ) for fires in the east domain excluding WRF domain 2. Fires for the north central domain have consistent scaling factors of 2.6 on average (IQR 2.2 to 3.3). After these, the south central and southeast domain have scaling factors of 1.2 (IQR 0.8 to 1.6) and 1.1 (IQR 0.6 to 1.6 ), respectively. The scaling factor for the West domain has a large variation, ranging from 3.9 to 10.1, but with the full range extending to zero values. The rest of the domains have very low scaling factors. Northern Canada has an inter-quartile range of 0.02 to 0.17 and Alaska and the pacific northwest have zero values. Fires within WRF domain 2 , close to the measurement site, also have scaling factors of 0 .

Figure 10 shows the inverted time series (given by $\mathbf{H} \boldsymbol{x}$ ) along with the original measurements $(\boldsymbol{y})$. The median Pearson correlation coefficient $(r)$ between the two is 0.39 for the complete time series and 0.58 when excluding the times removed by the residual scaling. The background value determined from the model is $1.99 \mathrm{ngm}^{-3}$ (IQR 1.98 to $2.01 \mathrm{ng} \mathrm{m}^{-3}$ ) and is very stable across model configurations (see Table 5). Rutter et al. (2008) measured a background concentration of $1.5 \mathrm{ng} \mathrm{m}^{-3}$ at a rural site $150 \mathrm{~km}$ to the west. This suggests that we can split the simulated background into a global component of $1.5 \mathrm{ng} \mathrm{m}^{-3}$ and a local and regional component of $0.49 \mathrm{ng} \mathrm{m}^{-3}$. In addition to the background concentration term, there is a missing term due to the discrepancy between the average measured concentrations of $2.48 \mathrm{ng} \mathrm{m}^{-3}$ and the average of the model inversion time series of $2.33 \mathrm{ng} \mathrm{m}^{-3}$. This leaves an unaccounted for gap of $0.15 \mathrm{ng} \mathrm{m}^{-3}$.

The time series of the contribution from the gridded emissions, the forest fires and the lake surface emissions are shown in the bottom panel of Fig. 10. The gridded emissions are assumed to be constant throughout the year and vary at both daily and synoptic time scales depending on the prevailing wind directions. The forest fires time series has a clear seasonal component which comes directly from the a priori emissions as the inverse method was not set up to deal with the temporal distribution of emissions. The highest contribution occurs during the high GEM event of April 2005 as well as during the smaller but more frequent events during fall 2004. The lake surface emissions are temperature dependent and therefore have a similar seasonal pattern, except that they are less influenced by individual events. Compared with the forest fires impacts, the lake surface also contributes to the April 2005 event, but it has a more continuous impact during the late summer of 2004. There are sporadic lake surface impacts at the measurement site throughout the fall, winter and spring.

\subsection{Impacts of estimated source groups on average GEM concentrations}

Table 5 shows the impacts of specific source groups on the average GEM concentrations at the receptor site. The results for the grid domains are aggregated from the grid cell impacts shown in Fig. 11. The table shows the median values 


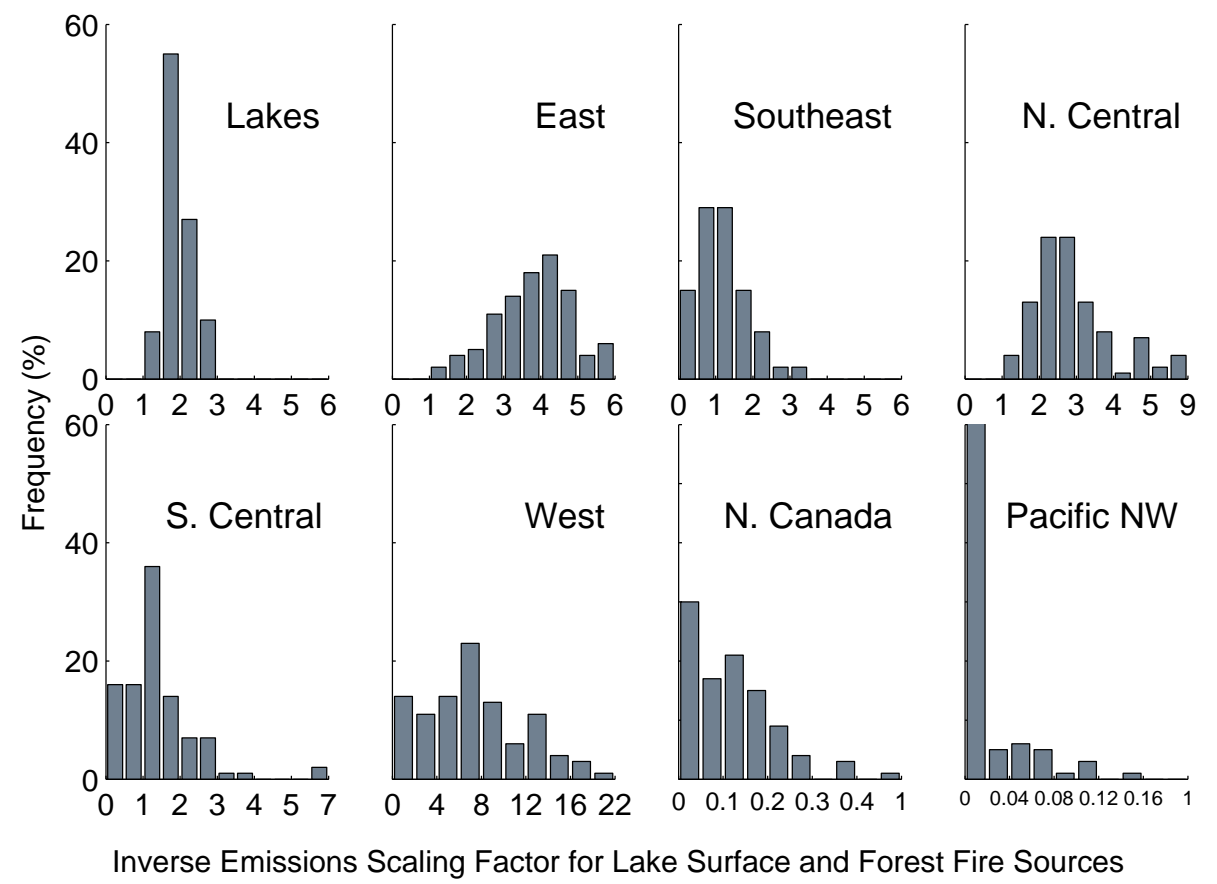

Fig. 9. Histograms of inverse emissions scaling factors for emissions from the Great Lakes and from forest fires by domain. See Fig. 2 for map of lake emissions and Fig. 3 for map of forest fire emissions. (Note that factors for Alaska and WRF D2 are always 0.)

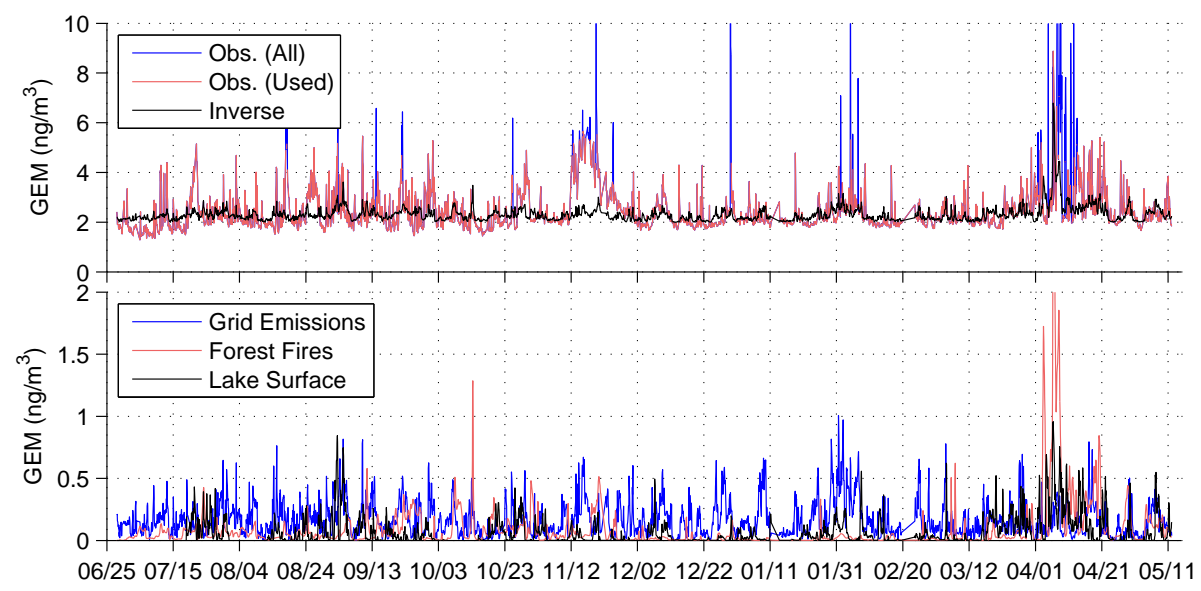

Fig. 10. Top: Measurements used in inversion (red), measurements excluded using residucal scaling (blue), and inverse time series of GEM. Bottom: Concentration contributions to the inverted time series of the grid, forest fire and lake surface emissions, June 2004 to May 2005.

and the inter-quartile range from the bootstrapped runs. Figure 12 shows the impacts from the inverse model for the Great Lakes, the forest fires and the gridded emissions by geographical domain.

The largest contributions to the inverted time series is from the global background $\left(1.5 \mathrm{ng} \mathrm{m}^{-3}\right)$ which is to be expected as GEM is a global pollutant with a long lifetime. The next two largest contributions are from the additional local and regional background $\left(0.49 \mathrm{ng} \mathrm{m}^{-3}\right)$ and from the discrepancy between the averages of the simulations and measurements $\left(0.15 \mathrm{ng} \mathrm{m}^{-3}\right)$. When the inverse method cannot resolve com- ponents of the measurement time series, it either represents them as a uniform background, or it leaves them out of the analysis which contributes to the discrepancy term. In Section 4.2 we will use a time scale analysis to identify the possible sources corresponding to these sources.

The remaining contributions are $188 \mathrm{pg} \mathrm{m}^{-3}$ from the gridded emissions, $86 \mathrm{pg} \mathrm{m}^{-3}$ from the forest fires and $61 \mathrm{pg} \mathrm{m}^{-3}$ from the lake surface emissions. The impacts due to the gridded emissions, shown in Fig. 11 are the product of the estimated emissions of a grid cell times the impact of that grid cell on the measurement site, obtained from the 


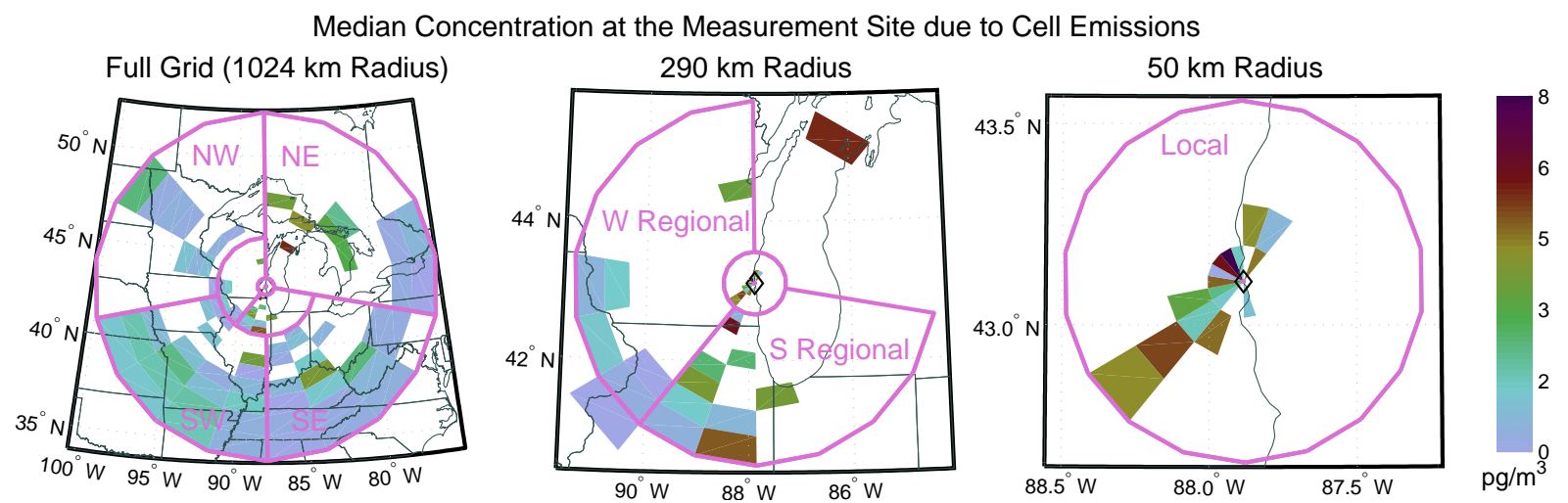

Fig. 11. Map of impacts at the receptor site. Color indicates the average GEM concentration at the measurement site due to emissions in that cell. Domain names and boundaries used in Tables 3 and 5 shown in pink. Areas with zero emissions shown in white.

Table 5. Contribution of different source groups to the annual average GEM concentration $\left(\mathrm{pg} \mathrm{m}^{-3}\right)$ at the receptor site.

\begin{tabular}{|c|c|c|c|c|}
\hline \multicolumn{2}{|c|}{ Source group } & \multirow{2}{*}{$\begin{array}{r}\text { Median } \\
63.8\end{array}$} & \multirow{2}{*}{$\begin{array}{r}\text { Lower-quartile } \\
54.1\end{array}$} & \multirow{2}{*}{$\begin{array}{r}\text { Upper-quartile } \\
71.7\end{array}$} \\
\hline Grids & Local (50 km radius) & & & \\
\hline & South regional & 29.7 & 25.8 & 35.9 \\
\hline & Northeast & 26.6 & 21.0 & 33.6 \\
\hline & Southeast & 16.2 & 13.1 & 19.4 \\
\hline & West regional & 15.8 & 11.5 & 21.7 \\
\hline & Southwest & 22.9 & 19.0 & 25.0 \\
\hline & Northwest & 10.6 & 8.2 & 14.2 \\
\hline \multicolumn{2}{|c|}{ Total Grid } & 187.9 & 177.3 & 202.2 \\
\hline \multirow[t]{9}{*}{ Fires } & WRF d2 & 0.0 & 0.0 & 0.0 \\
\hline & East & 46.2 & 36.6 & 52.8 \\
\hline & Southeast & 11.6 & 6.2 & 16.5 \\
\hline & South central & 8.2 & 5.6 & 10.7 \\
\hline & North central & 10.6 & 8.8 & 13.4 \\
\hline & West & 5.5 & 3.2 & 8.3 \\
\hline & Pacific northwest & 0.0 & 0.0 & 0.4 \\
\hline & Northern Canada & 4.2 & 0.7 & 6.3 \\
\hline & Alaska & 0.0 & 0.0 & 0.0 \\
\hline \multicolumn{2}{|c|}{ Total Fires } & 86.2 & 61.0 & 108.3 \\
\hline \multicolumn{2}{|c|}{ Lake surface } & 61.2 & 53.8 & 71.5 \\
\hline \multicolumn{2}{|c|}{ Local and regional background } & 490.0 & 480.0 & 510.0 \\
\hline \multicolumn{2}{|c|}{ Global background } & 1500.0 & 1500.0 & 1500.0 \\
\hline \multicolumn{2}{|c|}{ Unaccounted for in model } & 149.2 & 144.3 & 150.4 \\
\hline \multirow{2}{*}{\multicolumn{2}{|c|}{$\begin{array}{l}\text { Inverted time series } \\
\text { Measurements }\end{array}$}} & 2330.3 & 2323.9 & 2341.1 \\
\hline & & 2479.5 & 2468.2 & 2491.4 \\
\hline
\end{tabular}

Residence Time Analysis. The large sources from the southeast and the southwest can be seen to contribute $16 \mathrm{pg} \mathrm{m}^{-3}$ and $23 \mathrm{pg} \mathrm{m}^{-3}$, which are low values because the air mass in Milwaukee does not often come from those directions (see Fig. 6). The middle panel of Fig. 11 shows that the regional impacts from the south are mainly due to the Chicago area with an estimated contribution of $30 \mathrm{pg} \mathrm{m}^{-3}$. The main contributor from the gridded emissions are the local sources with impacts of $64 \mathrm{pg} \mathrm{m}^{-3}$. These can be seen in the right panel of Fig. 11 to be close to the source as well as to the southwest of the measurement site, which is the direction of the Menomonee valley industrial corridor.

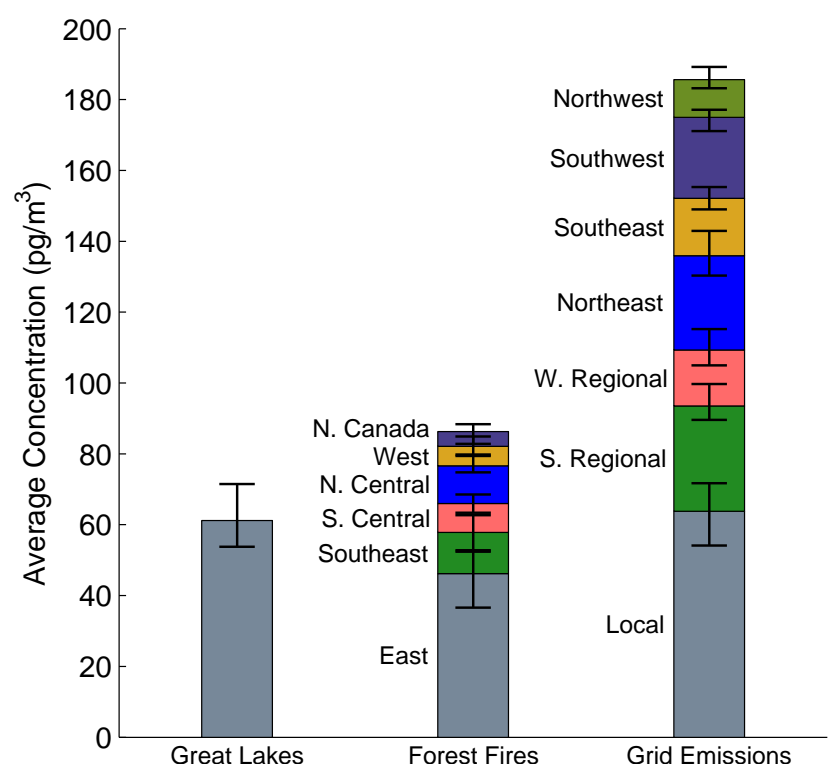

Fig. 12. Impacts from different source groups on the average GEM concentration at the measurement site. Error bars indicate the interquartile range of the inverse model estimates from the bootstrapped simulations. See also Table 5.

The fire contributions are mainly from the east domain, with average concentrations of $46 \mathrm{pg} \mathrm{m}^{-3}$. Next come the southeast, south central and north central domains with contributions of approximately $10 \mathrm{pg} \mathrm{m}^{-3}$. As noted above, the contributions from the west have a large uncertainty range, as do the ones from Northern Canada. The contributions from the the local fires, the pacific northwest and Alaska were all 0 . 
TRI Hg

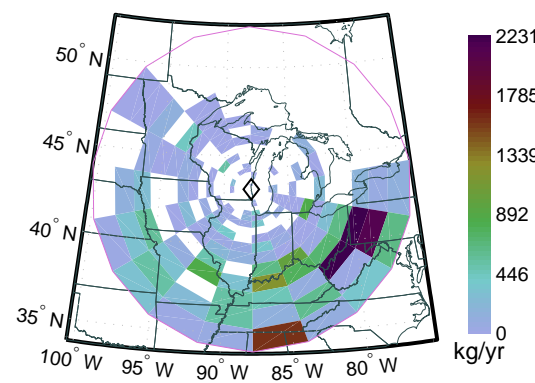

NEI GEM

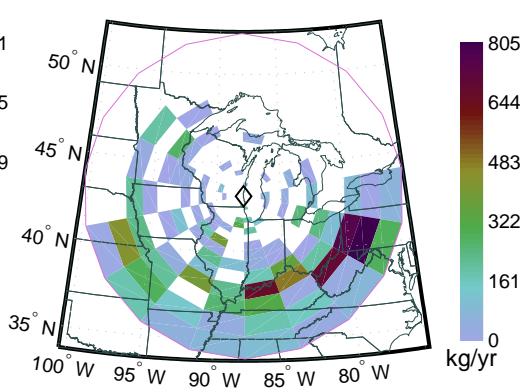

$\mathrm{NEI} \mathrm{Hg}$

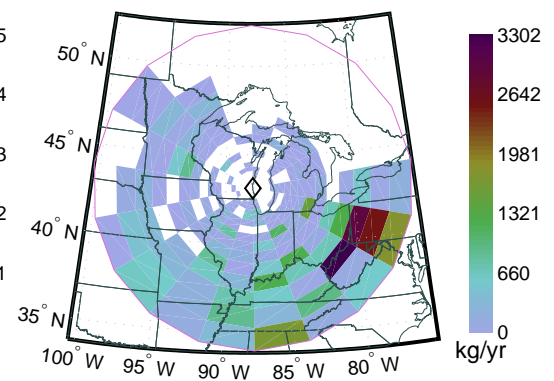

Fig. 13. Map of inventories of all mercury compounds from the Toxic Release Inventory (left), of GEM from the 2002 National Emissions Inventory (middle) and all ercury compounds from the 2002 NEI (right). Extent of the back-trajectory grid used for the inversion shown in pink. Areas with zero emissions shown in white.

\section{Discussion}

\subsection{Comparison with the Toxic Release Inventory and National Emissions Inventory}

The estimated gridded emissions in Fig. 8 can be compared with the US emissions from the 2004 Toxic Release Inventory (TRI) and those from the 2002 National Emissions Inventory (NEI), as shown in Fig. 13. TRI version 10 files were obtained from the US Environmental Protection Agency's website. These contain separate emission values for mercury and mercury compounds, which have been added together in the present work. The 2002 NEI Hazardous Air Pollutant inventory was obtained for point sources, using the files dated 23 January 2008 also available from the EPA's website. These contain separate values for elemental mercury, gaseous divalent mercury, particulate divalent mercury as well as two additional categories called "mercury" and "mercury and compounds". Here we use the emissions of elemental mercury as well as the total of all mercury types put together.

Total emissions are listed by domain in Table 3 for comparison with the model results. In terms of spatial distribution, the Ohio River Valley clearly stands out as it did in the model results. The two different inventories are in agreement on these sources with magnitudes within a factor of 2 of each other. The model estimated sources were in the range (IQR) of 19761 to $26391 \mathrm{~kg} \mathrm{yr}^{-1}$, compared with TRI emissions of $17658 \mathrm{~kg} \mathrm{yr}^{-1}$ and NEI emissions of $6035 \mathrm{~kg} \mathrm{yr}^{-1}$ for elemental mercury and $25603 \mathrm{~kg} \mathrm{yr}^{-1}$ counting all mercury emission types.

There are emissions from the southwest, but these are smaller than would be expected from the model by at least a factor of 2. A similar situation holds for the northwest and for the regional sources, with model results about 3 times higher than the TRI. The values for the northeast cannot be compared directly, as they do not include the emissions from Canada. Finally, the local emissions estimated by the model are a factor of 4 higher than the TRI, and a factor of 5 higher than the total mercury emissions from the NEI.

Part of the discrepancy maybe due to the fact that the inventories only include point sources for mercury. Had it been possible, including area sources could reduce the difference with the inverse model results. On the other hand, the synthetic test revealed that in the case of a simple source, the model tended to overestimate total emissions even though it identified the location of the source accurately. It is therefore reasonable to place greater confidence in the spatial pattern and relative magnitude of the emissions than in the absolute emission totals. Nevertheless, on balance the analysis does suggest that the emissions inventories underestimate elemental mercury emissions from sources other than the large coalfired power plants.

\subsection{Time scale analysis}

Table 5 above showed that $0.15 \mathrm{ng} \mathrm{m}^{-3}(6 \%)$ of GEM was unaccounted for by the model and $0.49 \mathrm{ng} \mathrm{m}^{-3}(20 \%)$ of GEM was included in the term for local and regional background.

In order to identify the sources contributing to these terms, we perform a time scale analysis as described by Hogrefe et al. (2003) and Hogrefe et al. (2001). We use the Kolmogorov-Zurbenko filter to separate the time series according to the temporal scale of the signal. The concentrations are split into intra-day, diurnal, synoptic and seasonal components. Note that for simplicity, we use the same coefficients as Hogrefe et al. (2003), although that means that our categories include longer time scales because we have data on alternate hours rather than every hour. The contribution of each temporal component to the full time series is obtained by calculating the variance of each component as a fraction of the sum of the variances of all the components.

Table 6 shows the results for the measurement time series, the inverted time series and the residual. This shows clearly that the measurements have components that vary across the whole range of times scales with roughly 
Table 6. Time scale analysis of the measurements, the inverted time series and the residual. This shows the percent of variance in the time series due to components with different time scales. The measurements contains variations at all time scales, but the inverted time series does not account sufficiently for hourly variations.

\begin{tabular}{lccc}
\hline Time scale & Measurement & Inverted time series & Residual \\
\hline Intra-day & 29 & 7 & 34 \\
Diurnal & 24 & 23 & 29 \\
Synoptic & 24 & 43 & 21 \\
Seasonal & 23 & 27 & 16 \\
\hline
\end{tabular}

similar contributions from each category. In contrast, the inverted time series is much lower on the intra-day component, which accounts for $7 \%$ instead of $29 \%$ of the variance. Correspondingly, the synoptic scale accounts for a greater fraction of the variance ( $43 \%$ instead of $24 \%$ ). For the residual, the components are highest in the intra-day scale and lowest in the seasonal scale.

This demonstrates that the inverse model is missing some of the high frequency components of the time series. These are due to short spikes in concentrations, which are most likely to be local sources where the plume has not had as much time to dilute. This suggests that the method is more likely to underestimate sources that are close by. Consequently, it can be inferred that a significant fraction of the unaccounted mercury is due to local sources.

When the inverse method cannot match high frequency peaks, it compensates by increasing the background term to obtain similar average levels of GEM over the entire time period. This suggests that local sources which cannot be resolved by the model contribute to the local and regional background term. As a result, this analysis is in agreement with Rutter et al. (2008) who suggest that one third of GEM is from local point sources.

\subsection{Lake, forest fire and volcano emissions}

The results of this analysis suggest that the emissions of GEM from the lake surfaces are two times higher than those calculated in Sect. 2.4. As noted above, there is considerable spread in the measured concentrations of dissolved gaseous mercury. The inverse model suggests that average values may be towards the higher end of the reported range, well above the $30 \mathrm{pgl}^{-1}$ used in the calculations. This would suggest average fluxes in the range of 4 to $5 \mathrm{ng} \mathrm{m}^{-2} \mathrm{~h}^{-1}$ and total emissions from the Great Lakes of 12000 to $14000 \mathrm{~kg}$ of GEM for the time period of the study.

Forest fires were found to have a clearly detectable signal in the GEM time series, with total impacts around $30 \%$ higher than the lake surface impacts. Most of these are due to emissions in the east domain which includes a large part of the midwest, the northeast and Southeastern Canada. The inverse model suggests that emissions from this area could be underestimated by a factor of 3 to 4 . The model further suggests that emissions in the north central domain could be underestimated by a factor of 2 to 3 , but that estimates of the emissions form the south central and southeast domains are of the correct magnitude. The domains further away were found to have nil or variable impacts. This could be because there is not enough data in the inversion, either because those areas do not influence the measurement site often enough, or because the level of the impacts is too low relative to other sources. Finally, the FINN model estimated releases of $1383 \mathrm{~kg}$ of mercury in WRF domain 2, close to the measurement site. The inverse model did not identify any impacts from these. This could be because local sources have short, sharp peaks which can easily suffer from mismatches between the model and the measurements or because the diurnal distribution of the emissions is more important for local sources. As with the gridded emissions, the inverse model does a better job of identifying sources that are further away than near-field ones.

There was one large episode of elevated GEM concentrations starting on 12 November 2004 and lasting until the end of the month which is not accounted for in the inversion, see Fig. 10. Levels rose rapidly to between 4 and $6 \mathrm{ng} \mathrm{m}^{-3}$ and decayed slowly over the next 2 weeks. This suggests a large regional source, but the event is puzzling because it lasted over a variety of wind patterns with shifting air masses from both the north and the south. Volcanoes can emit large amounts of mercury during explosions (Bagnato et al., 2011) and could be a possible source. Mount St. Helens in Washington State had renewed eruptions between September 2004 and December 2005 and could possibly be a factor in this event (Sherrod et al., 2008). We simulated forward emissions from the volcano using CAMx in combination with the large WRF domain used for forest fires. Although this source cannot be ruled out, the results did not provide strong evidence in support of this hypothesis.

Grímsvötn in Iceland had a week long eruption starting on 1 November 2004 (Thordarson and Larsen, 2007). We performed forward particle simulations using FLEXPART based on wind fields from the Global Forecast System. Although the arrival time matched the episode in the time series, the simulated concentrations lasted much longer than the measured episode itself. It would therefore seem that such a distant source cannot be responsible for such a clearly defined event. Nevertheless, further analysis of this event may be warranted especially if it can be expanded with concurrent measurements from different sites.

\section{Conclusions}

This paper developed a hybrid inversion scheme based on particle back-trajectories and forward Eulerian modeling to evaluate sources of elemental mercury using atmospheric measurements in Milwaukee. The method provided estimates 
of source strengths as well as source impacts at the measurement site. Using bootstrapping, the method further provided confidence intervals on the results.

Identifying local point sources is a particular challenge. The analysis therefore required a combination of analysis methods including meteorological analysis, concentration field analysis and time scale analysis to supplement the inverse method.

Average GEM concentrations in Milwaukee were $2.5 \mathrm{ngm}^{-3} .61 \%$ of this is due to the global background concentration of $1.5 \mathrm{ng} \mathrm{m}^{-3}$. The inverse method ascribed $20 \%$ to the local and regional background and did not account for another $6 \%$. Time scale analysis suggested that most of this is due to variations in concentrations on an hourly scale which could be attributed to local sources. The remaining $13 \%$ was split as follows: $26 \%$ from forest fires, $18 \%$ from lake surface emissions and $56 \%$ from local and regional sources covered by the inversion grid. Within this grid, the emissions estimate of the coal-fired power plants in the Ohio River Valley were in good agreement with current inventories. Sources in other areas were under-represented in the current inventories. In particular, local sources could be up to a factor of 4 or 5 higher, and sources in the southwest quadrant could be up to a factor of 2 higher. These sources may include waste disposal as well as metal processing. Overall, this study is consistent with Rutter et al. (2008) who suggest that there is a large urban excess of GEM in Milwaukee, and that one third of the GEM could be due to local sources.

The impacts of emissions from the lake surface and from forest fires could be clearly seen in the model inversion. These suggest that emissions from both of these sources are larger than predicted by current emissions models and that they contribute $2.5 \%$ and $3.5 \%$ to overall GEM levels in Milwaukee.

As the inversion uses a hybrid model, it is straightforward to simulate candidate sources using a chemical transport model and include them in the analysis. Soil and vegetation sources could be included in the same way as the lake surface sources. Further examples would depend on the location of the measurement site and could include testing the possibility of emissions from disparate sources such as melting snow or the magnitude of emissions from gold mining and underground coal fires.

Acknowledgements. This manuscript was made possible by EPA grant number RD-83455701. Its contents are solely the responsibility of the grantee and do not necessarily represent the official views of the EPA. Further, the EPA does not endorse the purchase of any commercial products or services mentioned in the publication. The initial mercury measurements were funded by US EPA STAR Grant \# R829798. We are also grateful to the US EPA for making the National Emissions Inventory and Toxic Release Inventory available, and to the US National Climatic Data Center for the meteorological data. We are grateful to the two anonymous referees whose careful reviews improved the quality of this paper.

Edited by: R. Harley

\section{References}

Akagi, S. K., Yokelson, R. J., Wiedinmyer, C., Alvarado, M. J., Reid, J. S., Karl, T., Crounse, J. D., and Wennberg, P. O.: Emission factors for open and domestic biomass burning for use in atmospheric models, Atmos. Chem. Phys., 11, 4039-4072, doi:10.5194/acp-11-4039-2011, 2011.

Ashbaugh, L. L., Malm, W. C., and Sadeh, W. Z.: A residence time probability analysis of sulfur concentrations at grand-canyonnational-park, Atmos. Environ., 19, 1263-1270, 1985.

Aster, R. C., Borchers, B., and Turber, C. H.: Parameter Estimation and Inverse Problems, Academic Press, second edn., 2012.

Bagnato, E., Aiuppa, A., Parello, F., Allard, P., Shinohara, H., Liuzzo, M., and Giudice, G.: New clues on the contribution of Earth's volcanism to the global mercury cycle, Bull. Volcan., 73, 497-510, doi:10.1007/s00445-010-0419-y, 2011.

Bash, J., Miller, D., Meyer, T., and Bresnahan, P.: Northeast United States and Southeast Canada natural mercury emissions estimated with a surface emission model, Atmos. Environ., 38, 5683-5692, doi:10.1016/j.atmosenv.2004.05.058, 2004.

Bash, J. O.: Description and initial simulation of a dynamic bidirectional air-surface exchange model for mercury in Community Multiscale Air Quality (CMAQ) model, J. Geophys. Res.Atmos., 115, doi:10.1029/2009JD012834, 2010.

Bash, J. O. and Miller, D. R.: A relaxed eddy accumulation system for measuring surface fluxes of total gaseous mercury, J. Atmos. Ocean. Technol., 25, 244-257, doi:10.1175/2007JTECHA908.1, 2008.

Brioude, J., Kim, S.-W., Angevine, W. M., Frost, G. J., Lee, S.H., McKeen, S. A., Trainer, M., Fehsenfeld, F. C., Holloway, J. S., Ryerson, T. B., Williams, E. J., Petron, G., and Fast, J. D.: Top-down estimate of anthropogenic emission inventories and their interannual variability in Houston using a mesoscale inverse modeling technique, J. Geophys. Res.-Atmos., 116, D20305, doi:10.1029/2011JD016215, 2011.

Bullock, Jr., O. R., Atkinson, D., Braverman, T., Civerolo, K., Dastoor, A., Davignon, D., Ku, J.-Y., Lohman, K., Myers, T. C., Park, R. J., Seigneur, C., Selin, N. E., Sistla, G., and Vijayaraghavan, K.: The North American Mercury Model Intercomparison Study (NAMMIS): Study description and modelto-model comparisons, J. Geophys. Res.-Atmos., 113, D17310, doi:10.1029/2008JD009803, 2008.

Carroll, M., Townshend, J., Hansen, M., DiMiceli, C., Sohlberg, R., and Wurster, K.: Vegetative Cover Conversion and Vegetation Continuous Fields, in: Land Remote Sensing and Global Environmental Change: NASA's Earth Observing System and the Science of Aster and MODIS, edited by: Ramachandran, B., Justice, C. O., and Abrams, M., Springer-Verlag, doi:10.1007/9781-4419-6749-7, 2011.

Cheng, I., Lu, J., and Song, X.: Studies of potential sources that contributed to atmospheric mercury in Toronto, Canada, Atmos. Environ., 43, 6145-6158, doi:10.1016/j.atmosenv.2009.09.008, 2009. 
Cheng, I., Zhang, L., Blanchard, P., Graydon, J. A., and Louis, V. L. S.: Source-receptor relationships for speciated atmospheric mercury at the remote Experimental Lakes Area, northwestern Ontario, Canada, Atmos. Chem. Phys., 12, 1903-1922, doi:10.5194/acp-12-1903-2012, 2012.

Ci, Z., Zhang, X., and Wang, Z.: Elemental mercury in coastal seawater of Yellow Sea, China: Temporal variation and air-sea exchange, Atmos. Environ., 45, 183-190, doi:10.1016/j.atmosenv.2010.09.025, 2011a.

Ci, Z. J., Zhang, X. S., Wang, Z. W., Niu, Z. C., Diao, X. Y., and Wang, S. W.: Distribution and air-sea exchange of mercury $(\mathrm{Hg})$ in the Yellow Sea, Atmos. Chem. Phys., 11, 2881-2892, doi:10.5194/acp-11-2881-2011, 2011b.

Cohen, M., Artz, R., Draxler, R., Miller, P., Poissant, L., Niemi, D., Ratte, D., Deslauriers, M., Duval, R., Laurin, R., Slotnick, J., Nettesheim, T., and McDonald, J.: Modeling the atmospheric transport and deposition of mercury to the Great Lakes, Environ. Res., 95, 247-265, doi:10.1016/j.envres.2003.11.007, 2004.

de Foy, B., Lei, W., Zavala, M., Volkamer, R., Samuelsson, J., Mellqvist, J., Galle, B., Martinez, A. P., Grutter, M., Retama, A., and Molina, L. T.: Modelling constraints on the emission inventory and on vertical dispersion for $\mathrm{CO}$ and $\mathrm{SO} 2$ in the Mexico City Metropolitan Area using Solar FTIR and zenith sky UV spectroscopy, Atmos. Chem. Phys., 7, 781-801, doi10.5194/acp-7781-2007, 2007.

de Foy, B., Zavala, M., Bei, N., and Molina, L. T.: Evaluation of WRF mesoscale simulations and particle trajectory analysis for the MILAGRO field campaign, Atmos. Chem. Phys., 9, 44194438, doi10.5194/acp-9-4419-2009, 2009.

de Foy, B., Smyth, A. M., Thompson, S. L., Gross, D. S., Olson, M. R., Sager, N., and Schauer, J. J.: Sources of Nickel, Vanadium and Black Carbon in Aerosols in Milwaukee, Atmos. Environ., 59, 294-301, doi:10.1016/j.atmosenv.2012.06.002, 2012.

Doran, J. C., Fast, J. D., Barnard, J. C., Laskin, A., Desyaterik, Y., and Gilles, M. K.: Applications of Lagrangian dispersion modeling to the analysis of changes in the specific absorption of elemental carbon, Atmos. Chem. Phys., 8, 1377-1389, doi10.5194/acp-8-1377-2008, 2008.

Eckhardt, S., Prata, A. J., Seibert, P., Stebel, K., and Stohl, A.: Estimation of the vertical profile of sulfur dioxide injection into the atmosphere by a volcanic eruption using satellite column measurements and inverse transport modeling, Atmos. Chem. Phys., 8, 3881-3897, doi10.5194/acp-8-3881-2008, 2008.

Engle, M. A., Tate, M. T., Krabbenhoft, D. P., Schauer, J. J., Kolker, A., Shanley, J. B., and Bothner, M. H.: Comparison of atmospheric mercury speciation and deposition at nine sites across central and eastern North America, J. Geophys. Res.-Atmos., 115, D18306, doi:10.1029/2010JD014064, 2010.

Enting, I. G.: Inverse Problems in Atmospheric Constituent Transport, Cambridge University Press, UK, p. 51, 2002.

ENVIRON: CAMx, comprehensive air quality model with extensions, User's Guide, Tech. Rep. Version 5.40, ENVIRON International Corporation, 2011.

Fast, J. D. and Easter, R.: A Lagrangian Particle Dispersion Model Compatible with WRF, in: 7th WRF User's Workshop, Boulder, CO, USA, 2006.

Friedl, M. A., Sulla-Menashe, D., Tan, B., Schneider, A., Ramankutty, N., Sibley, A., and Huang, X.: MODIS Collection 5 global land cover: Algorithm refinements and characteriza- tion of new datasets, Remote Sens. Environ., 114, 168-182, doi:10.1016/j.rse.2009.08.016, 2010.

Gbor, P., Wen, D., Meng, F., Yang, F., Zhang, B., and Sloan, J.: Improved model for mercury emission, transport and deposition, Atmos. Environ., 40, 973-983, doi:10.1016/j.atmosenv.2005.10.040, 2006.

Gbor, P. K., Wen, D., Meng, F., Yang, F., and Sloan, J. J.: Modeling of mercury emission, transport and deposition in North America, Atmos. Environ., 41, 1135-1149, doi:10.1016/j.atmosenv.2006.10.005, 2007.

Giglio, L., Descloitres, J., Justice, C., and Kaufman, Y.: An enhanced contextual fire detection algorithm for MODIS, Remote Sens. Environ., 87, 273-282, doi:10.1016/S00344257(03)00184-6, 2003.

Han, Y., Holsen, T., Hopke, P., and Yi, S.: Comparison between back-trajectory based modeling and Lagrangian backward dispersion Modeling for locating sources of reactive gaseous mercury, Environ. Sci. Technol., 39, 1715-1723, doi:10.1021/es0498540, 2005.

Han, Y.-J., Holsen, T. M., and Hopke, P. K.: Estimation of source locations of total gaseous mercury measured in New York State using trajectory-based models, Atmos. Environ., 41, 6033-6047, doi:10.1016/j.atmosenv.2007.03.027, 2007.

Hansen, M., Townshend, J., Defries, R., and Carroll, M.: Estimation of tree cover using MODIS data at global, continental and regional/local scales, Int. J. Remote Sens., 26, 4359-4380, 2005.

Hansen, M. C., DeFries, R. S., Townshend, J. R. G., Carroll, M., Dimiceli, C., and Sohlberg, R. A.: Global Percent Tree Cover at a Spatial Resolution of 500 Meters: First Results of the MODIS Vegetation Continuous Fields Algorithm, Earth Interact., 7, 115, 2003.

Hansen, P. C.: Discrete Inverse Problems: Insight and Algorithms, SIAM - Soc. Industr. Appl. Math., 53-105, 2010.

Henze, D. K., Seinfeld, J. H., and Shindell, D. T.: Inverse modeling and mapping US air quality influences of inorganic $\mathrm{PM}(2.5)$ precursor emissions using the adjoint of GEOS-Chem, Atmos. Chem. Phys., 9, 5877-5903, doi10.5194/acp-9-5877-2009, 2009.

Hoelzemann, J., Schultz, M., Brasseur, G., Granier, C., and Simon, M.: Global Wildland Fire Emission Model (GWEM): Evaluating the use of global area burnt satellite data, J. Geophys. Res.Atmos., 109, D14S04, doi:10.1029/2003JD003666, 2004.

Hogrefe, C., Rao, S., Kasibhatla, P., Hao, W., Sistla, G., Mathur, R., and McHenry, J.: Evaluating the performance of regionalscale photochemical modeling systems: Part II - ozone predictions, Atmos. Environ., 35, 4175-4188, doi:10.1016/S13522310(01)00183-2, 2001.

Hogrefe, C., Vempaty, S., Rao, S., and Porter, P.: A comparison of four techniques for separating different time scales in atmospheric variables, Atmos. Environ., 37, 313-325, doi:10.1016/S1352-2310(02)00897-X, 2003.

Hong, S. Y., Noh, Y., and Dudhia, J.: A new vertical diffusion package with an explicit treatment of entrainment processes, Mon. Weather Rev., 134, 2318-2341, 2006.

Huang, J., Choi, H.-D., Hopke, P. K., and Holsen, T. M.: Ambient Mercury Sources in Rochester, NY: Results from Principle Components Analysis (PCA) of Mercury Monitoring Network Data, Environ. Sci. Technol., 44, 8441-8445, doi:10.1021/es102744j, 2010. 
Kain, J. S.: The Kain-Fritsch convective parameterization: An update, J. Appl. Meteorol., 43, 170-181, 2004.

Kolker, A., Olson, M. L., Krabbenhoft, D. P., Tate, M. T., and Engle, M. A.: Patterns of mercury dispersion from local and regional emission sources, rural Central Wisconsin, USA, Atmos. Chem. Phys., 10, 4467-4476, doi:10.5194/acp-10-4467-2010, 2010.

Kuss, J., Holzmann, J., and Ludwig, R.: An Elemental Mercury Diffusion Coefficient for Natural Waters Determined by Molecular Dynamics Simulation, Environ. Sci. Technol., 43, 3183-3186, doi:10.1021/es8034889, 2009.

Lai, S.-O., Holsen, T. M., Han, Y.-J., Hopke, P. P., Yi, S.-M., Blanchard, P., Pagano, J. J., and Milligan, M.: Estimation of mercury loadings to Lake Ontario: Results from the Lake Ontario atmospheric deposition study (LOADS), Atmos. Environ., 41, 82058218, doi:10.1016/j.atmosenv.2007.06.035, 2007.

Lauvaux, T., Uliasz, M., Sarrat, C., Chevallier, F., Bousquet, P., Lac, C., Davis, K. J., Ciais, P., Denning, A. S., and Rayner, P. J.: Mesoscale inversion: first results from the CERES campaign with synthetic data, Atmos. Chem. Phys., 8, 3459-3471, doi10.5194/acp-8-3459-2008, 2008.

Lin, C., Lindberg, S., Ho, T., and Jang, C.: Development of a processor in BEIS3 for estimating vegetative mercury emission in the continental United States, Atmos. Environ., 39, 7529-7540, doi:10.1016/j.atmosenv.2005.04.044, 7th International Conference on Mercury as a Global Pollutant, Ljubljana, SLOVENIA, 28 June-2 July 2004, 2005.

Lin, X. and Tao, Y.: A numerical modelling study on regional mercury budget for eastern North America, Atmos. Chem. Phys., 3, 535-548, doi10.5194/acp-3-535-2003, 2003.

Lindberg, S., Bullock, R., Ebinghaus, R., Engstrom, D., Feng, X., Fitzgerald, W., Pirrone, N., Prestbo, E., and Seigneur, C.: A synthesis of progress and uncertainties in attributing the sources of mercury in deposition, Ambio, 36, 19-32, 8th International Conference on Mercury as a Global Pollutant, Madison, WI, AUG 06-11, 2006, 2007.

Liu, B., Keeler, G. J., Dvonch, J. T., Barres, J. A., Lynam, M. M., Marsik, F. J., and Morgan, J. T.: Urban-rural differences in atmospheric mercury speciation, Atmos. Environ., 44, 2013-2023, doi:10.1016/j.atmosenv.2010.02.012, 2010.

Lorenc, A. C.: Analysis Methods for Numerical Weather Prediction, Q. J. R. Meteorol. Soc., 112, 1177-1194, 1986.

Manning, A. J.: The challenge of estimating regional trace gas emissions from atmospheric observations, Phil. Trans. Roy. Soc. A - Math. Phys. Eng. Sci., 369, 1943-1954, doi:10.1098/rsta.2010.0321, 2011.

Manning, A. J., O’Doherty, S., Jones, A. R., Simmonds, P. G., and Derwent, R. G.: Estimating UK methane and nitrous oxide emissions from 1990 to 2007 using an inversion modeling approach, J. Geophys. Res.-Atmos., 116, D02305, doi:10.1029/2010JD014763, 2011.

Manolopoulos, H., Schauer, J. J., Purcell, M. D., Rudolph, T. M., Olson, M. L., Rodger, B., and Krabbenhoft, D. P.: Local and regional factors affecting atmospheric mercury speciation at a remote location, J. Environ. Eng. Sci., 6, 491-501, doi:10.1139/S07-005, 2007a.

Manolopoulos, H., Snyder, D. C., Schauer, J. J., Hill, J. S., Turner, J. R., Olson, M. L., and Krabbenhoft, D. P.: Sources of speciated atmospheric mercury at a residential neighborhood impacted by industrial sources, Environ. Sci. Technol., 41, 5626-
5633, doi:10.1021/es0700348, 2007b.

Mergler, D., Anderson, H. A., Chan, L. H. M., Mahaffey, K. R., Murray, M., Sakamoto, M., and Stern, A. H.: Methylmercury exposure and health effects in humans: A worldwide concern, Ambio, 36, 3-11, 8th International Conference on Mercury as a Global Pollutant, Madison, WI, 6-11 August 2006, 2007.

Mesinger, F., DiMego, G., Kalnay, E., Mitchell, K., Shafran, P., Ebisuzaki, W., Jovic, D., Woollen, J., Rogers, E., Berbery, E., Ek, M., Fan, Y., Grumbine, R., Higgins, W., Li, H., Lin, Y., Manikin, G., Parrish, D., and Shi, W.: North American regional reanalysis, B. Am. Meteorol. Soc., 87, 343-360, doi:10.1175/BAMS-87-3343, 2006.

Murray, M. and Holmes, S.: Assessment of mercury emissions inventories for the Great Lakes states, Environ. Res., 95, 282-297, doi:10.1016/j.envres.2004.02.007, Workshop on an Ecosystem Approach to the Health Effects of Mercury in the Great Lakes Basin, Windsor, Canada, 26-27 Feburary 2003, 2004.

O'Brien, J. J.: A note on the vertical structure of the eddy exchange coefficient in the planetary boundary layer, J. Atmos. Sci., 27, 1214-1215, 1970.

Pirrone, N., Cinnirella, S., Feng, X., Finkelman, R. B., Friedli, H. R., Leaner, J., Mason, R., Mukherjee, A. B., Stracher, G. B., Streets, D. G., and Telmer, K.: Global mercury emissions to the atmosphere from anthropogenic and natural sources, Atmos. Chem. Phys., 10, 5951-5964, doi:10.5194/acp-10-5951-2010, 2010.

Poissant, L., Amyot, M., Pilote, M., and Lean, D.: Mercury water-air exchange over the Upper St. Lawrence River and Lake Ontario, Environ. Sci. Technol., 34, 3069-3078, doi:10.1021/es990719a, 2000.

Rigby, M., Manning, A. J., and Prinn, R. G.: Inversion of long-lived trace gas emissions using combined Eulerian and Lagrangian chemical transport models, Atmos. Chem. Phys., 11, 9887-9898, doi:10.5194/acp-11-9887-2011, 2011.

Roedenbeck, C., Gerbig, C., Trusilova, K., and Heimann, M.: A two-step scheme for high-resolution regional atmospheric trace gas inversions based on independent models, Atmos. Chem. Phys., 9, 5331-5342, doi10.5194/acp-9-5331-2009, 2009.

Roustan, Y. and Bocquet, M.: Inverse modelling for mercury over Europe, Atmos. Chem. Phys., 6, 3085-3098, doi10.5194/acp-63085-2006, 2006.

Rutter, A. P., Schauer, J. J., Lough, G. C., Snyder, D. C., Kolb, C. J., Von Klooster, S., Rudolf, T., Manolopoulos, H., and Olson, M. L.: A comparison of speciated atmospheric mercury at an urban center and an upwind rural location, J. Environ. Monitor., 10, 102-108, doi:10.1039/b710247j, 2008.

Schroeder, W. and Munthe, J.: Atmospheric mercury - An overview, Atmos. Environ., 32, 809-822, doi:10.1016/S13522310(97)00293-8, 4th International Conference on Mercury as a Global Pollutant, Hamburg, Germany, AUG 04-08, 1996, 1998.

Seibert, P.: Inverse modelling of sulfur emissions in Europe based on trajectories, in: Inverse Methods in Global Biogeochemical Cycles, edited by: Kasibhatla, P., Heimann, M., Rayner, P., Mahowald, N., Prinn, R. G., and Hartley, D. E., 114, Geophys. Monogr., 147-154, Am. Geophys. Union, 2000.

Seibert, P., Kromp-Kolb, H., Baltensperger, U., Jost, D. T., and Schwikowski, M.: Trajectory analysis of high-alpine air pollution data, in: Air Pollution Modelling and its Application X, edited by: Gryning, S.-E. and Millan, M. M., pp. 595-596, Plenum 
Press, New York, USA, 1994.

Seigneur, C.: Estimating the Contribution of Coal-Fired Power Plants to the Atmospheric Deposition of Mercury in Wisconsin, Tech. Rep. CP263-1a, Atmospheric and Environmental Research, Inc., 2007.

Seigneur, C., Vijayaraghavan, K., Lohman, K., Karamchandani, P., and Scott, C.: Global source attribution for mercury deposition in the United States, Environ. Sci. Technol., 38, 555-569, doi:10.1021/es034109t, 2004.

Selin, N. E.: Global Biogeochemical Cycling of Mercury: A Review, Ann. Rev. Environ. Resour., 34, 43-63, doi:10.1146/annurev.environ.051308.084314, 2009.

Sherrod, D. R., Scott, W. E., and Stauffer, P. H.: A Volcano rekindled: The Renewed Eruption of Mount St. Helens, 2004 2006, Tech. rep., US Geological Survey, http://pubs.er.usgs.gov/ publication/pp1750, 2008.

Sigler, J. M., Mao, H., and Talbot, R.: Gaseous elemental and reactive mercury in Southern New Hampshire, Atmos. Chem. Phys., 9, 1929-1942, doi10.5194/acp-9-1929-2009, 2009.

Skamarock, W. C., Klemp, J. B., Dudhia, J., Gill, D. O., Barker, D. M., Wang, W., and Powers, J. G.: A Description of the Advanced Research WRF Version 2, Tech. Rep. NCAR/TN468+STR, NCAR, 2005.

Slemr, F., Brunke, E. G., Ebinghaus, R., and Kuss, J.: Worldwide trend of atmospheric mercury since 1995, Atmos. Chem. Phys., 11, 4779-4787, doi:10.5194/acp-11-4779-2011, 2011.

Soerensen, A. L., Sunderland, E. M., Holmes, C. D., Jacob, D. J., Yantosca, R. M., Skov, H., Christensen, J. H., Strode, S. A., and Mason, R. P.: An Improved Global Model for Air-Sea Exchange of Mercury: High Concentrations over the North Atlantic, Environ. Sci. Technol., 44, 8574-8580, doi:10.1021/es102032g, 2010.

Sprovieri, F., Pirrone, N., Ebinghaus, R., Kock, H., and Dommergue, A.: A review of worldwide atmospheric mercury measurements, Atmos. Chem. Phys., 10, 8245-8265, doi:10.5194/acp10-8245-2010, 2010.

Stohl, A., Forster, C., Frank, A., Seibert, P., and Wotawa, G.: Technical note: The Lagrangian particle dispersion model FLEXPART version 6.2, Atmos. Chem. Phys., 5, 2461-2474, doi10.5194/acp-5-2461-2005, 2005.

Stohl, A., Seibert, P., Arduini, J., Eckhardt, S., Fraser, P., Greally, B. R., Lunder, C., Maione, M., Muehle, J., O’Doherty, S., Prinn, R. G., Reimann, S., Saito, T., Schmidbauer, N., Simmonds, P. G., Vollmer, M. K., Weiss, R. F., and Yokouchi, Y.: An analytical inversion method for determining regional and global emissions of greenhouse gases: Sensitivity studies and application to halocarbons, Atmos. Chem. Phys., 9, 1597-1620, doi:10.5194/acp-91597-2009, 2009.
Streets, D. G., Devane, M. K., Lu, Z., Bond, T. C., Sunderland E. M., and Jacob, D. J.: All-Time Releases of Mercury to the Atmosphere from Human Activities, Environ. Sci. Technol., 45 , 10485-10491, doi:10.1021/es202765m, 2011.

Tarantola, A.: Inverse Problem Theory, Methods for Data Fitting and Model Parameter Estimation, Elsevier, Philadelphia, PA, USA, p. 64, 1987.

Thompson, R. L., Gerbig, C., and Roedenbeck, C.: A Bayesian inversion estimate of $\mathrm{N} 2 \mathrm{O}$ emissions for western and central Europe and the assessment of aggregation errors, Atmos. Chem. Phys., 11, 3443-3458, doi:10.5194/acp-11-3443-2011, 2011.

Thordarson, T. and Larsen, G.: Volcanism in Iceland in historical time: Volcano types, eruption styles and eruptive history, Journal of Geodynamics, 43, 118-152, doi:10.1016/j.jog.2006.09.005, 2007.

Vette, A., Landis, M., and Keeler, G.: Deposition and emission of gaseous mercury to and from Lake Michigan during the Lake Michigan Mass Balance Study (July, 1994 October, 1995), Environ. Sci. Technol., 36, 4525-4532, doi:10.1021/es0112184, 2002.

Wanninkhof, R.: Relationship Between Wind Speed and Gas Exchange Over the Ocean, J. Geophys. Res.-Atmos., 97, 7373$7382,1992$.

Wen, D., Lin, J. C., Meng, F., Gbor, P. K., He, Z., and Sloan, J. J.: Quantitative assessment of upstream source influences on total gaseous mercury observations in Ontario, Canada, Atmos. Chem. Phys., 11, 1405-1415, doi:10.5194/acp-11-1405-2011, 2011.

Wiedinmyer, C. and Friedli, H.: Mercury emission estimates from fires: An initial inventory for the United States, Environ. Sci. Technol., 41, 8092-8098, doi:10.1021/es071289o, 2007.

Wiedinmyer, C., Quayle, B., Geron, C., Belote, A., McKenzie, D., Zhang, X., O’Neill, S., and Wynne, K. K.: Estimating emissions from fires in North America for air quality modeling, Atmos. Environ., 40, 3419-3432, doi:10.1016/j.atmosenv.2006.02.010, 2006.

Wiedinmyer, C., Akagi, S. K., Yokelson, R. J., Emmons, L. K., AlSaadi, J. A., Orlando, J. J., and Soja, A. J.: The Fire INventory from NCAR (FINN): a high resolution global model to estimate the emissions from open burning, Geosci. Model Dev., 4, 625641, doi:10.5194/gmd-4-625-2011, 2011.

Wunsch, C.: Discrete Inverse and State Estimation Problems: With Geophysical Fluid Applications, Cambridge University Press, 2006.

Yarwood, G., Lau, S., Jia, Y., Karamchandani, P., and Vijayaraghavan, K.: Modeling Atmospheric Mercury Chemistry and Deposition with CAMx for a 2002 Annual Simulations, Tech. rep., ENVIRON International Corporation, 2003. 